\title{
A Pyrolysis Mechanism for Ammonia
}

\author{
D. F. DAVIDSON, K. KOHSE-HÖINGHAUS*, A. Y. CHANG, \\ and R.K. HANSON \\ High Temperature Gasdynamics Laboratory, Department of Mechanical Engineering, \\ Stanford University, Stanford, California 94305
}

\begin{abstract}
The mechanism of $\mathrm{NH}_{3}$ pyrolysis was investigated over a wide range of conditions behind reflected shock waves. Quantitative time-history measurements of the species $\mathrm{NH}$ and $\mathrm{NH}_{2}$ were made using narrow-linewidth laser absorption. These records were used to establish an improved model mechanism for ammonia pyrolysis. The risetime and peak concentrations of $\mathrm{NH}$ and $\mathrm{NH}_{2}$ in this experimental database have also been summarized graphically.

Rate coefficients for several reactions which influence the $\mathrm{NH}$ and $\mathrm{NH}_{2}$ profiles were fitted in the temperature range $2200 \mathrm{~K}$ to $2800 \mathrm{~K}$. The reaction and the corresponding best fit rate coefficients are as follows:

$$
\mathrm{NH}_{2}+\mathrm{H} \longrightarrow \mathrm{NH}+\mathrm{H}_{2}
$$

with a rate coefficient of $4.0 \times 10^{13} \exp (-3650 / R T) \mathrm{cm}^{3} \mathrm{~mol}^{-1} \mathrm{~s}^{-1}$,

$$
\mathrm{NH}_{2}+\mathrm{NH} \longrightarrow \mathrm{N}_{2} \mathrm{H}_{2}+\mathrm{H}
$$

with a rate coefficient of $1.5 \times 10^{15} T^{-0.5} \mathrm{~cm}^{3} \mathrm{~mol}^{-1} \mathrm{~s}^{-1}$ and

$$
\mathrm{NH}_{2}+\mathrm{NH}_{2} \longrightarrow \mathrm{NH}+\mathrm{NH}_{3}
$$

with a rate coefficient of $5.0 \times 10^{13} \exp (-10000 / R T) \mathrm{cm}^{3} \mathrm{~mol}^{-1} \mathrm{~s}^{-1}$. The uncertainty in rate coefficient magnitude in each case is estimated to be $\pm 50 \%$. The temperature dependences of these rate coefficients are based on previous estimates.

The experimental data from four earlier measurements of the dissociation reaction

$$
\mathrm{NH}_{3}+\mathrm{M} \longrightarrow \mathrm{NH}_{2}+\mathrm{H}+\mathrm{M}
$$

were reanalyzed in light of recent data for the rate of $\mathrm{NH}_{3}+\mathrm{H} \longrightarrow \mathrm{NH}_{2} 1+\mathrm{H}_{2}$, and an improved rate coefficient of $2.2 \times 10^{16} \exp (-93470 / R T) \mathrm{cm}^{3} \mathrm{~mol}^{-1} \mathrm{~s}^{-1}$ in the temperature range 1740 to $3300 \mathrm{~K}$ was obtained. The uncertainty in the rate coefficient magnitude is estimated to be $\pm 15 \%$.
\end{abstract}

\section{Introduction}

The ammonia decomposition system has been extensively studied; see references below. The two primary reactions in the ammonia decomposition system, $\mathrm{NH}_{3}+\mathrm{M} \rightarrow \mathrm{NH}_{2}+\mathrm{H}+\mathrm{M}$ and $\mathrm{NH}_{3}+\mathrm{H} \rightarrow \mathrm{NH}_{2}+\mathrm{H}_{2}$, are sufficiently well characterized [1-5] that attention may now be focused on secondary reactions. For example, determinations of rate coefficients for certain of the reactions involving $\mathrm{NH}$ or $\mathrm{NH}_{2}$ should now be possible using a detailed model and profile-fitting procedures.

* On leave from DFVLR, Institut für Physikalische Chemie der Verbrennnung, D-7000 Stuttgart, W. Germany.

International Journal of Chemical Kinetics, Vol. 22, 513-535 (1990)

(c) 1990 John Wiley \& Sons, Inc.

CCC 0538-8066/90/050513-23\$04.00 
The verification of any kinetic mechanism is based on accurate quantitative measurements of the component species. At present, $\mathrm{H}$ and $\mathrm{N}$ ARAS (Atomic Resonance Absorption Spectrophotometry) measurements in shock tube experiments and atomic resonance fluorescence methods in flow reactors are capable of sensing ppm and sub-ppm levels in highly diluted systems [4-7]. $\mathrm{NH}$ can be measured quantitatively with a narrow-linewidth laser absorption diagnostic to a level of a few ppm $[8,9]$. The $\mathrm{NH}_{2}$ narrowlinewidth laser absorption diagnostic, though it is less sensitive and the absorption coefficient is less accurately known, can be used to measure levels to approximately $10 \mathrm{ppm}[10] . \mathrm{NH}_{3}$ has historically been measured by UV absorption or IR emission [1,3]. In addition to pyrolysis studies of $\mathrm{NH}_{3}$, photolysis methods are presently available using a flashlamp [5,7] or an excimer laser [11]. These new photolytic approaches have extended the useful range of temperatures available for shock tube studies of $\mathrm{N} / \mathrm{H}$ reactions below $2000 \mathrm{~K}$. Thus, over a wide range of experimental conditions, it is now possible to quantitatively measure several of the important species and thereby evaluate a full kinetic mechanism of $\mathrm{NH}_{3}$ decomposition.

Earlier ammonia pyrolysis measurements and mechanisms are summarized briefly below. As research in this field is extensive, only recently published representative studies are included.

Miller and Bowman [12] have recently reviewed the role of nitrogen chemistry in combustion. This article is a culmination of a series of articles by several workers which has introduced the role of $\mathrm{N}_{2} \mathrm{H}_{j}$ species into the ammonia mechanism [13-16].

Cohen [17], a theoretical review of the $\mathrm{O}+\mathrm{NH}_{2} \rightarrow \mathrm{NH}_{2}+\mathrm{OH}$ reaction, contains a discussion of many of the reactions involved in ammonia decomposition.

Saliman, Hanson, and Kruger [18,19] is a shock tube study of NO and $\mathrm{NH}_{3}$ kinetics. In their study, they followed the profiles of $\mathrm{OH}, \mathrm{NO}$, and $\mathrm{H}_{2} \mathrm{O}$ with narrowline laser absorption, of $\mathrm{NH}_{3}$ and $\mathrm{N}_{2} \mathrm{O}$ by IR emission, and of $\mathrm{NH}_{2}$ by visible emission. Their work, which uses a reaction set including the $\mathrm{N}_{2} \mathrm{H}_{j}$ species, is a continuation of a $\mathrm{NH}_{3} / \mathrm{NO}$ study begun by Roose $[1,20]$ in our laboratory.

Dean, Chou, and Stern [21] have measured $\mathrm{OH}, \mathrm{NH}$, and $\mathrm{NH}_{2}$ using laser absorption in atmospheric-pressure, rich ammonia flames. They have found that $\mathrm{NH}_{i}+\mathrm{NH}_{j}$ reactions dominate the kinetics in these rich flames, and they have estimated several of the relevant rate coefficients.

Dasch and Blint [22] have examined lean to stoichiometric ammoniaoxygen-nitrogen flames by measuring laser-induced fluorescence, flame speed, and post-flame $\mathrm{NO}_{x}$ concentration. They found that the $\mathrm{NH}_{i}+\mathrm{NH}_{j}$ reactions were not required in their modelling.

Dransfeld [23] performed direct studies of elementary reactions of $\mathrm{NH}_{2}$ at $300 \mathrm{~K}$ using LMR or LIF techniques. Holzrichter and Wagner [3] have examined $\mathrm{NH}_{3}$ decomposition at high temperatures in a shock tube with UV absorption.

Yumura and Asaba [4] performed a shock tube study of $\mathrm{NH}_{3}$ decomposition using $\mathrm{H}$ ARAS. This was one of a series of articles on $\mathrm{N} / \mathrm{H}$ chemistry [24-26]. 
Dove and $\mathrm{Nip}$ [2] identify $\mathrm{H}, \mathrm{NH}$, and $\mathrm{NH}_{2}$ as playing significant roles in high temperature $\mathrm{NH}_{3}$ decomposition and $\mathrm{NH}_{2}$ as playing a significant role in the formation of $\mathrm{N}_{2}$. They have derived relative concentration profiles of major species by time-resolved mass-spectroscopic analysis.

In the past decade several new facts relevant to the $\mathrm{NH}_{3}$ system have emerged. First, an improved measurement of the rate coefficient for reaction (2), $\mathrm{NH}_{3}+\mathrm{H} \rightarrow \mathrm{NH}_{2}+\mathrm{H}$, one of the primary reactions in $\mathrm{NH}_{3}$ pyrolysis, was made by Michael, Sutherland, and Klemm [5]. In their measured temperature range, their rate coefficient value was five times larger than that previously accepted. As all the determinations of reaction (1), $\mathrm{NH}_{3}+\mathrm{M} \rightarrow \mathrm{NH}_{2}+\mathrm{H}+\mathrm{M}$, are dependent on reaction (2) and were made several years previously, it was necessary to correct them. Second, the heats of formation of several species, in particular $\mathrm{NH}_{2}$, have been revised [27]. Finally, the role of $\mathrm{N}_{2} \mathrm{H}_{j}$ species in the kinetic mechanisms has become widely accepted. These three facts, as well as a general improvement in knowledge of $\mathrm{N} / \mathrm{H}$ reaction rate coefficients, have made this a suitable time to reexamine the ammonia pyrolysis mechanism.

\section{Experimental Technique}

The measurement of the $\mathrm{NH}$ and $\mathrm{NH}_{2}$ concentration profiles have been performed in a high purity stock tube using narrow-linewidth laser absorption diagnostics. The experimental apparatus, which has been fully detailed in another article [10] is only briefly described here.

The shock tube driven section was stainless steel, $6.1 \mathrm{~m}$ long, $14.3 \mathrm{~cm}$ in diameter. The system was bakeable to $80^{\circ} \mathrm{C}$ and was turbo-pumped. The ultimate pressure and the combined leak and outgassing rate were $9 \times 10^{-7}$ torr and $1.2 \times 10^{-6}$ torr $/ \mathrm{min}$, respectively. The gases in these experiments were used directly from Liquid Carbonic cylinders. The $\mathrm{NH}_{3}$ was $>99.99 \%$ pure, while the bulk carrier gas, argon, was $>99.999 \%$ pure. A passivation scheme was used in the shock tube to ensure that the mol fraction of $\mathrm{NH}_{3}$ was then established. The shock tube was passivated with the test mixture for $5 \mathrm{~min}$ and then pumped for 5 min prior to refilling the tube for the shock. Infrared emission measurements at $2-3.4 \mu \mathrm{m}$ were also used to verify the initial $\mathrm{NH}_{3}$ concentration within $\pm 5 \%$.

The diagnostic beam path was either 0.95 or $2.1 \mathrm{~cm}$ from the endwall of the shock tube. This resulted in typical incident shock-heating times of 40 to $80 \mu \mathrm{sec}$ (laboratory time). The temperature range and pressure in the incident shock region were 1000 to $1500 \mathrm{~K}$ and approximately $0.1 \mathrm{~atm}$. This brief preliminary heating does not significantly affect the modelling chemistry.

Shock velocities were determined using a series of four thin films. Reflected pressure and temperatures were calculated from these velocities using a frozen chemistry, 1-dimensional shock code. The long-time temperature behavior was confirmed using the laser-scanning temperature monitor described in Chang [28] and the long-time pressure behavior was confirmed by using a piezo-electric transducer. Over the approximately $1 \mathrm{~ms}$ of reflected shock test time, both the pressure and temperature were found to vary no more than the experimental uncertainty of $1.5 \%$. 
The narow-linewidth absorption laser diagnostic utilized a Spectra-Physics model 380 ring dye laser pumped either by a Spectra-Physics model 171 or 164 argon ion laser. The ring dye laser was run with Rhodamine 590 in the case of $\mathrm{NH}_{2}$ or DCM in the case of $\mathrm{NH}$. The $\mathrm{NH}_{2}$ was detected by absorption at $597.375 \mathrm{~nm}$ (vac), using the $A^{2} A_{1} \leftarrow X^{2} B_{1}(090 \leftarrow 000) \sum^{P} Q_{1, \mathrm{~N}}(7)$ doublet [10]. For NH, output of the ring dye laser was extracavity doubled with a $\mathrm{LiIO}_{3}$ crystal. The $\mathrm{NH}$ was detected by absorption using either the $A^{3} \Pi_{i} \leftarrow X^{3} \sum(0,0) Q_{1}$ band head at $336.100 \mathrm{~nm}$ or the single $Q_{2}(9)$ line at $336.060 \mathrm{~nm}[8]$.

The absorption coefficient for NH (used in the Beer-Lambert law conversion of the experimental absorption data to mol fraction) is directly related to the radiative lifetime of the upper state of the absorption transition [8]. The coefficient used here is based on a measurement of $420 \mathrm{~ns}$ for the lifetime of the $v=0$ level of $\mathrm{NH}\left(A^{3} \Pi_{i}\right)$ by Garland and Crosley [29]. This has been stated to be accurate within $2 \%$. This uncertainty is combined with the experimental uncertainty in locating the laser at the absorption peak $\left( \pm 0.02 \mathrm{~cm}^{-1}\right.$ on a $0.2 \mathrm{~cm}^{-1}$ FWHM line for $\mathrm{NH}_{2}$ and $\pm 0.04 \mathrm{~cm}^{-1}$ on a $0.30 \mathrm{~cm}^{-1} \mathrm{FWHM}$ line for $\mathrm{NH}$ ) and the uncertainty in determining the mol fraction which accrue from finite the signal-to-noise ratios, the errors in gas mixtures, and the shock tube temperaure determination. The overall uncertainty in mol fraction is $\pm 10 \%$.

In the case of $\mathrm{NH}_{2}$ there is at present no final consensus on the oscillator strength for the $A^{2} A_{1} \leftarrow X^{2} B_{1}(900 \leftarrow 000) \sum^{\mathrm{P}} Q_{1, \mathrm{~N}}(7)$ transition. This transition, a pair of overlapping lines, has also been described by a different notation [42]. Recent work in our laboratory by Kohse-Höinghaus [10] gives an absorption coefficient based on both kinetic and photolysis techniques. The claimed accuracy is $\pm 30 \%$. For the present work the pyrolysis $\mathrm{NH}_{2}$ profiles are self calibrating, as the early time $\mathrm{NH}_{2}$ behavior is well described by the two known reactions: (7), $\mathrm{NH}_{3}+\mathrm{M} \rightarrow \mathrm{NH}_{2}+\mathrm{H}+\mathrm{M}$, and (15), $\mathrm{NH}_{3}+\mathrm{H} \rightarrow \mathrm{NH}_{2}+\mathrm{H}_{2}$. Fitting the early time slope for each shock datum in the current study however, gives absorption coefficients consistent with the upper limits of the absorption coefficients given by KohseHöinghaus.

\section{Synopsis of the Experimental Database}

The pyrolysis experiments were conducted in the temperature range 2000 to $3200 \mathrm{~K}$, in the pressure range 1.1 to $0.8 \mathrm{~atm}$, and in the concentration range 0.1 to $1.0 \% \mathrm{NH}_{3}$. A small group of $\mathrm{NH}_{2}$ absorption experiments was conducted at 0.4 to $0.5 \mathrm{~atm}$. Examples of the data and the good fits obtained with the final mechanism are shown in Figures 1 to 4 .

To allow tests and comparisons of future revised mechanisms, the pyrolysis $\mathrm{NH}$ and $\mathrm{NH}_{2}$ peaks were characterized in two ways. The experimentally measured values of the peak concentration for both $\mathrm{NH}$ and $\mathrm{NH}_{2}$ are shown in Figure 5. The time interval between the arrival of the reflected shock front and the occurrence of the peak mol fraction (i.e., the "time-to-peak") is shown in Figure 6. The reflected shock pressures for these experiments are best described (independent of $\mathrm{NH}_{3}$ concentration) as $P=-3.25 \times 10^{6} T^{-2}+4.26 \times 10^{3} T^{-1}-0.236[\mathrm{~atm}]( \pm 3 \%)$. 


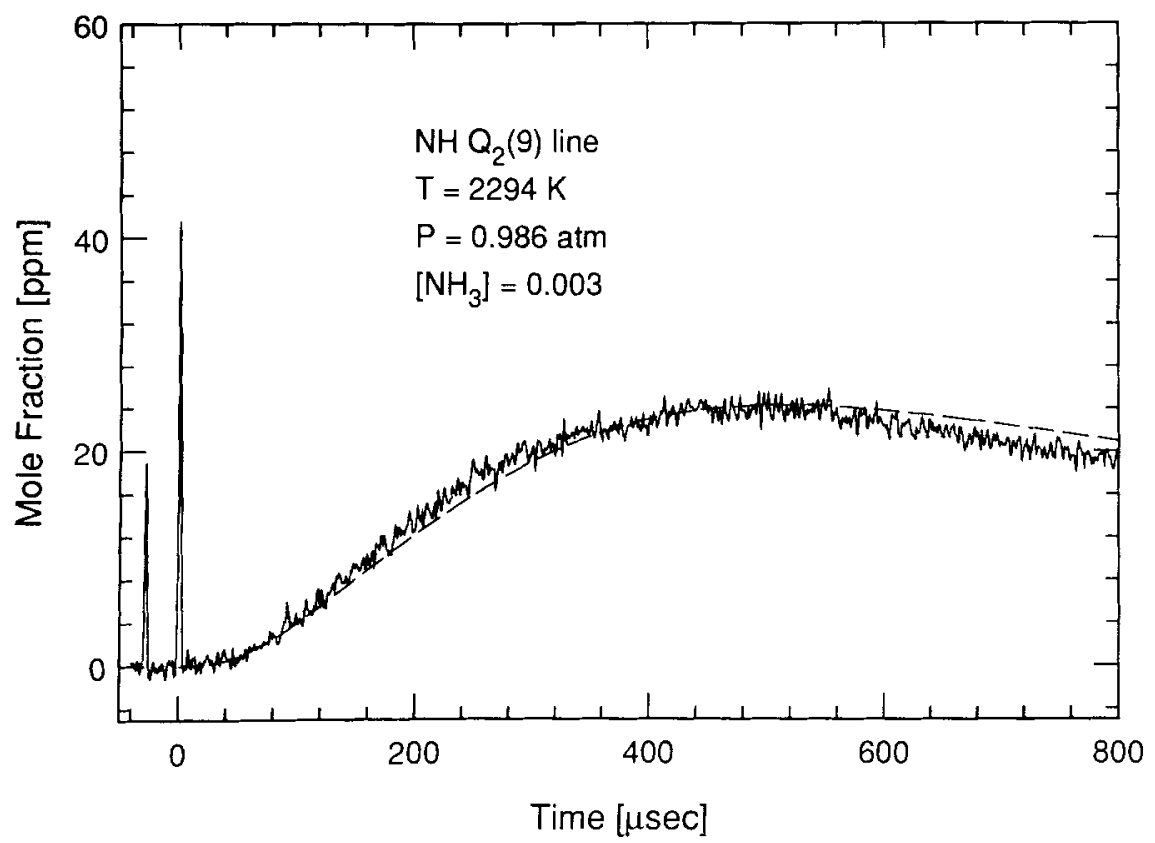

Figure 1. $\mathrm{NH}\left(Q_{2}(9)\right.$ line) absorption data and kinetic model. Reflected shock conditions are $\mathrm{T}=2294 \mathrm{~K}, P=0.986 \mathrm{~atm}$, and $\left[\mathrm{NH}_{3}\right]=0.003$. The two peaks at time 0 and $-30 \mu \mathrm{s}$ are the result of shock front induced beam steering.

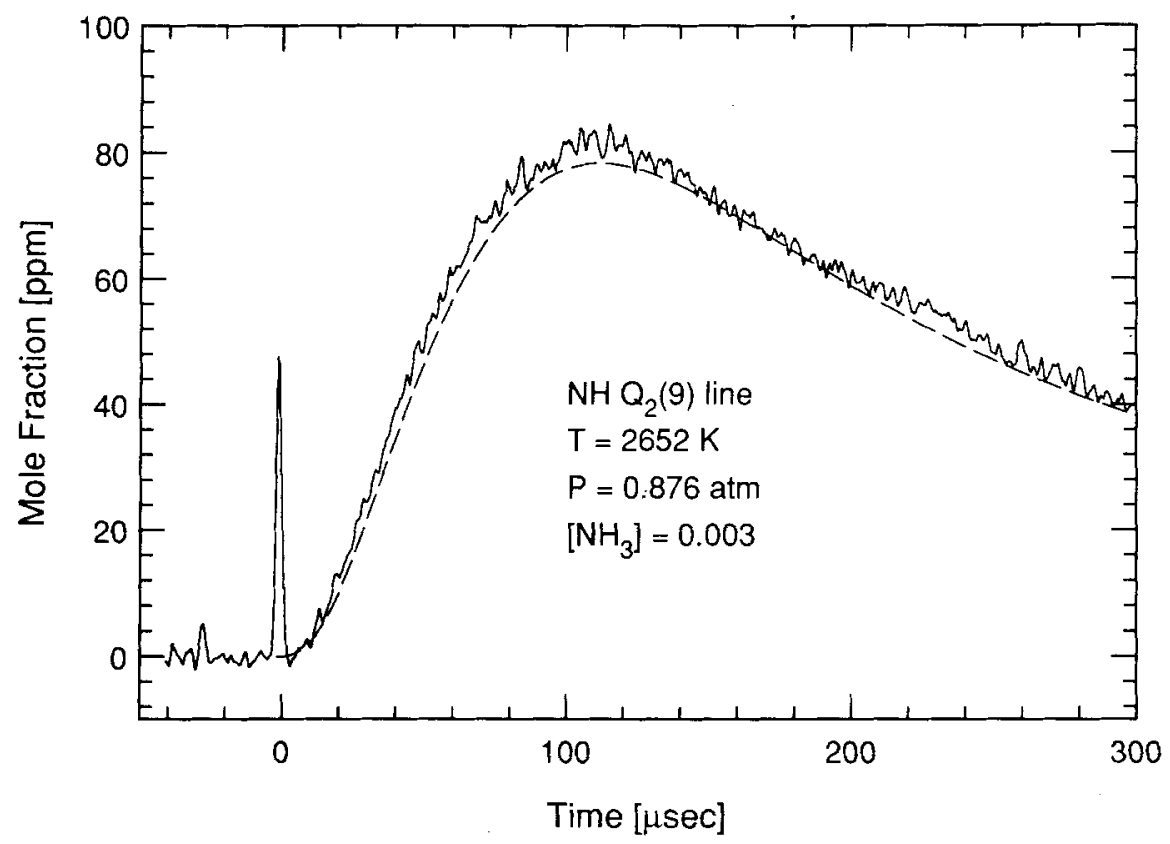

Figure 2. $\mathrm{NH}\left(Q_{2}(9)\right.$ line $)$ absorption data and kinetic model. Reflected shock conditions are $\mathrm{T}=2652 \mathrm{~K}, P=0.876 \mathrm{~atm}$, and $\left[\mathrm{NH}_{3}\right]=0.003$. 


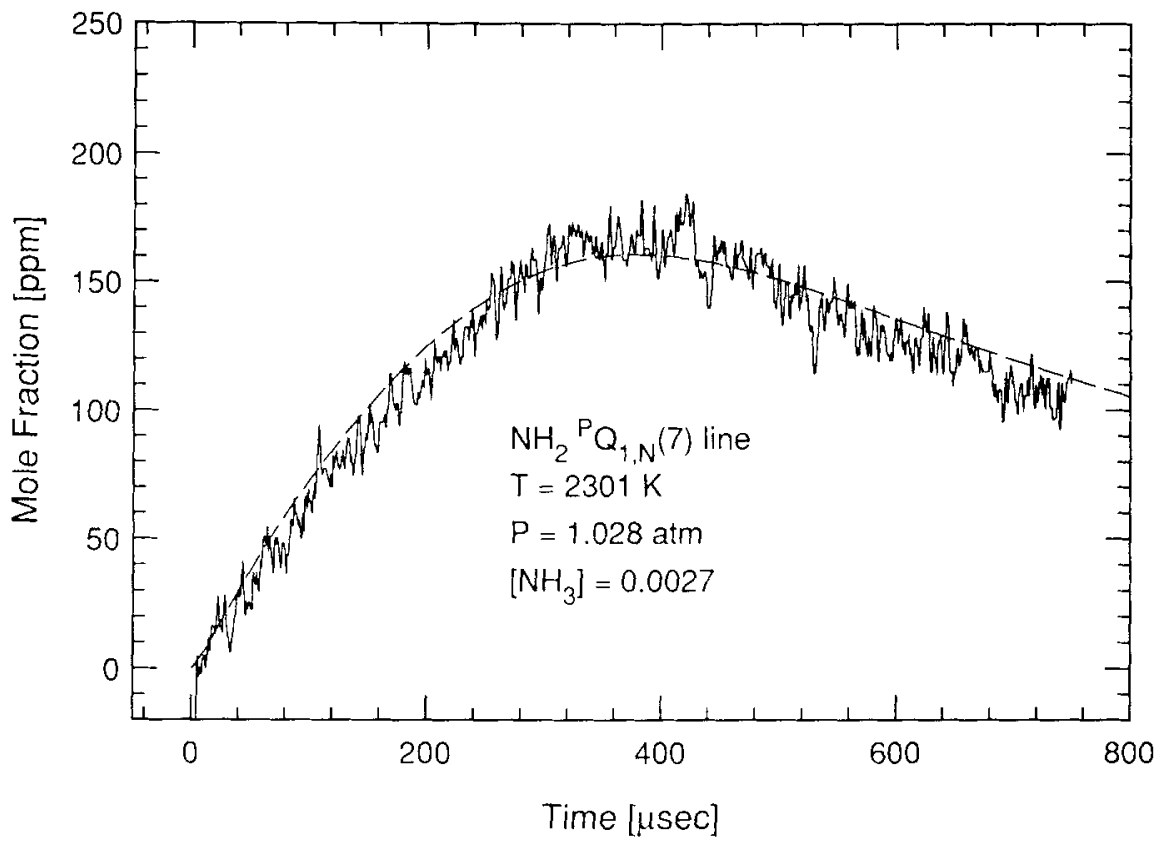

Figure 3. $\mathrm{NH}_{2}\left({ }^{P} Q_{1, N}(7)\right.$ line $)$ absorption data and kinetic model. Reflected shock conditions are $\mathrm{T}=2301 \mathrm{~K}, P=1.028 \mathrm{~atm}$, and $\left[\mathrm{NH}_{3}\right]=0.0027$.

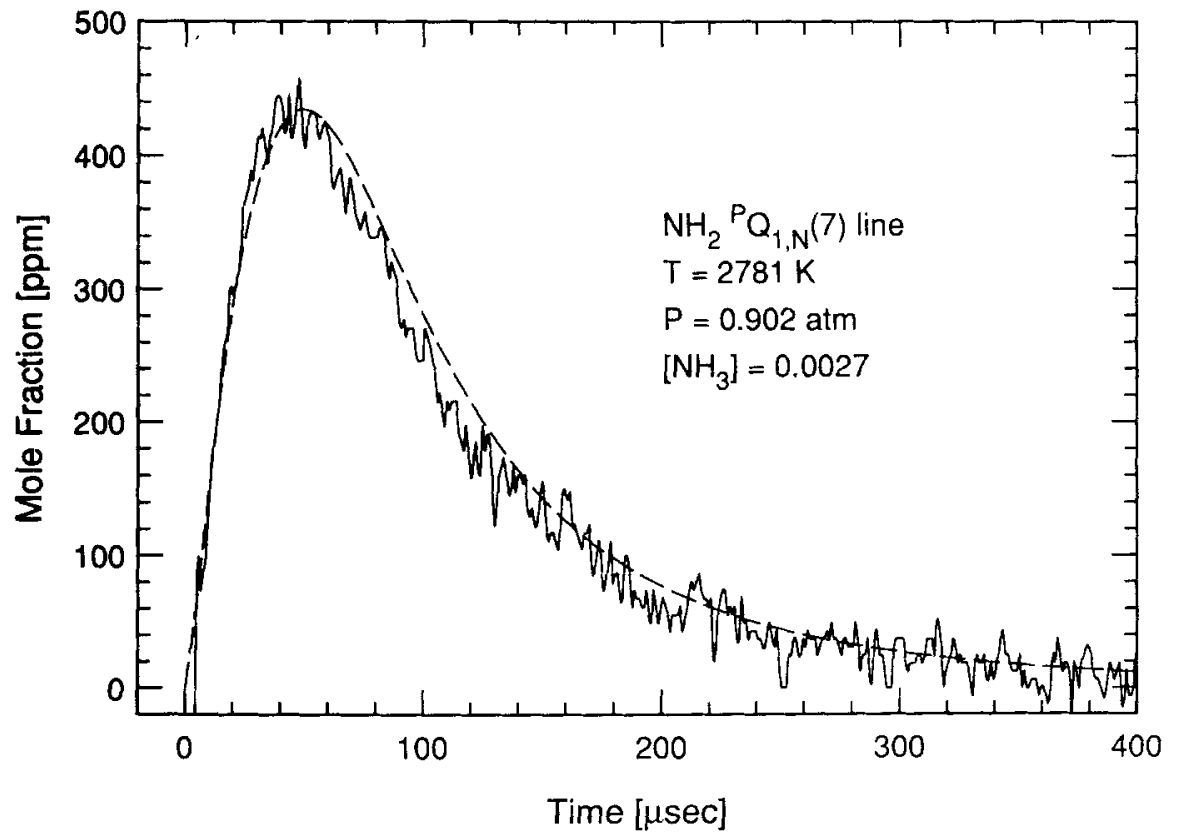

Figure 4. $\mathrm{NH}_{2}\left({ }^{P} Q_{1, N}(7)\right.$ line) absorption data and kinetic model. Reflected shock conditions are $\mathrm{T}=2781 \mathrm{~K}, P=0.902 \mathrm{~atm}$, and $\left[\mathrm{NH}_{3}\right]=0.0027$. 


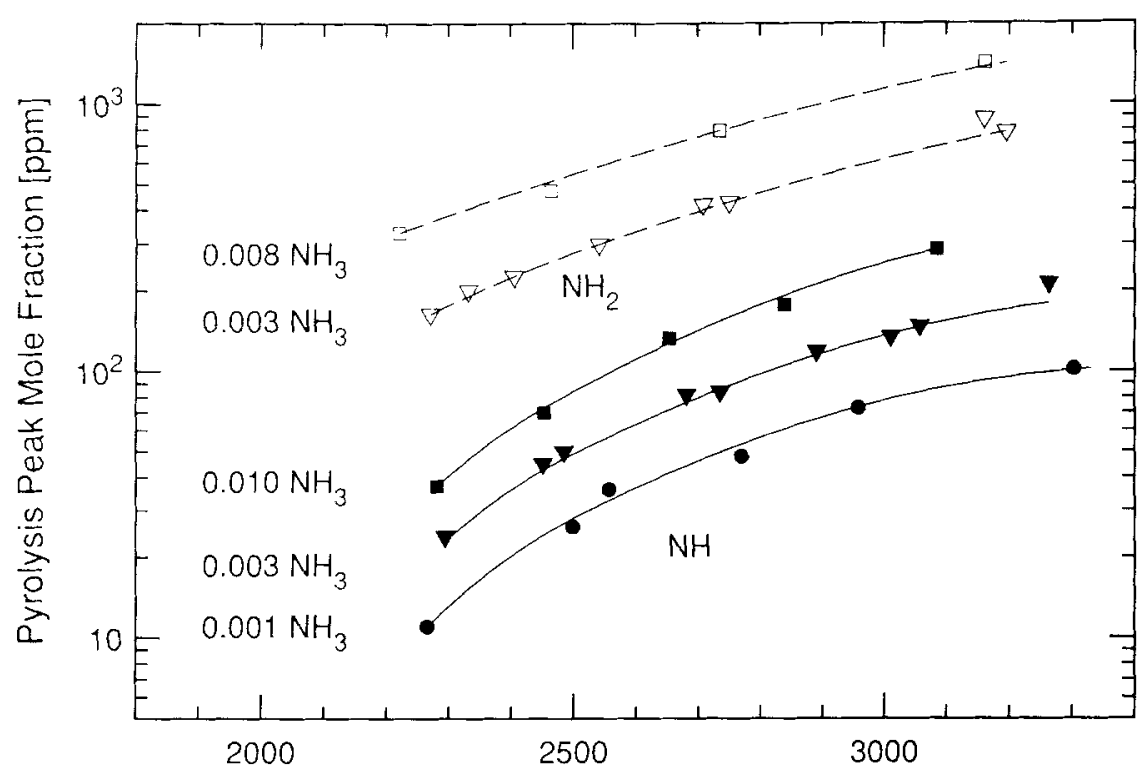

Figure 5. Peak mol fractions of $\mathrm{NH}$ and $\mathrm{NH}_{2}$ occurring during the pyrolysis of $\mathrm{NH}_{3}$. Best fit to our database is shown as lines. Solid lines and symbols are the NH peak values, and dashed lines and hollow symbols are the $\mathrm{NH}_{2}$ values. Circles: $0.001\left[\mathrm{NH}_{3}\right]$; trianges: $0.003\left[\mathrm{NH}_{3}\right]$; and squares: $0.008 / 0.01\left[\mathrm{NH}_{3}\right]$. The reflected shock pressures for the experiments in Figures 5 and 6 (independent of $\mathrm{NH}_{3}$ concentrations) are given by $P$ atm $]=-3.25 \times 10^{6} T^{-2}+4.26 \times 10^{3} T^{-1}-0.236( \pm 3 \%)$.

The $\mathrm{NH}_{2}$ time-to-peak are determined mainly by reaction (1), $\mathrm{NH}_{3}+$ $\mathrm{M} \rightarrow \mathrm{NH}_{2}+\mathrm{H}+\mathrm{M}$. Thus the time-to-peak values (at any fixed temperature and similar pressures) for all measured $\mathrm{NH}_{3}$ concentrations collapse to a single point. The $\mathrm{NH}_{2}$ times-to-peak for the $0.3 \% \mathrm{NH}_{3}, 0.4$ to $0.5 \mathrm{~atm}$ cases (done at half the pressure of the nominal 1 atm experiments) are twice as long.

\section{The Kinetic Model}

The complete mechanism is shown in Table I. A discussion of individual reactions included in (and excluded from) this mechanism is given in the Appendix. The mechanism is derived from the recent article by Miller and Bowman [12] and includes their relevant $\mathrm{N} / \mathrm{H}$ reactions.

Recent measurements of some NH reactions have provided more confidence in the secondary and tertiary reaction sequence of this mechanism. These recent measurements include the work of Mertens [9] on reactions (4), $\mathrm{NH}+\mathrm{M} \rightarrow \mathrm{N}+\mathrm{H}+\mathrm{M}$, and (7), $\mathrm{NH}+\mathrm{NH} \rightarrow \mathrm{N}_{2}+\mathrm{H}+\mathrm{H}$, and the work of Davidson [30] on reaction (5), $\mathrm{N}+\mathrm{H}_{2} \rightarrow \mathrm{H}+\mathrm{NH}$. Another recent work utilized is the room temperature study of reaction (1), $\mathrm{NH}+$ $\mathrm{NH}_{2} \rightarrow$ products, by Dransfeld [23].

Shown in Figure 7 are the kinetic modelling predictions for all the species which are expected to be present in a typical $\mathrm{NH}_{3}$ pyrolysis reflectedshock experiment at the conditions of $2500 \mathrm{~K}, 1 \mathrm{~atm}, 0.3 \% \mathrm{NH}_{3}$. The CHEMKIN program has been used for the computation (constant enthalpy, 


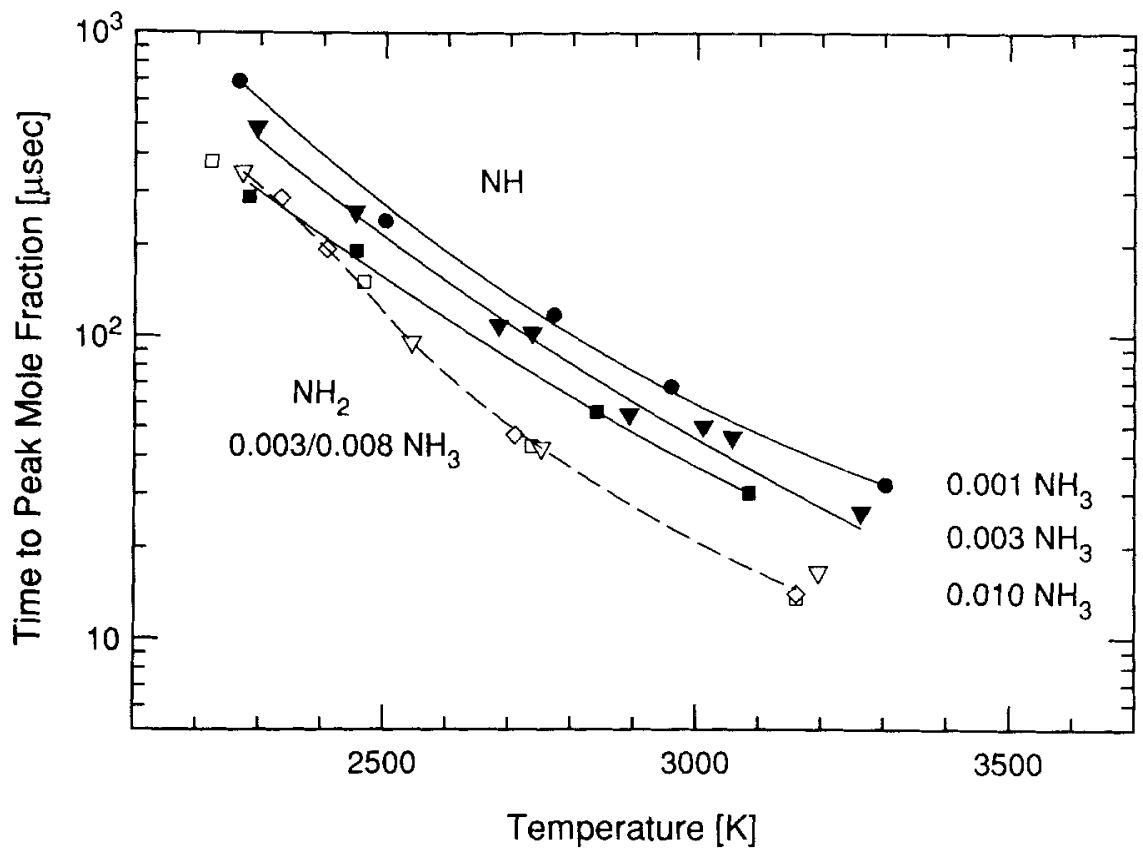

Figure 6. Time-to-peak mol fraction of $\mathrm{NH}$ and $\mathrm{NH}_{2}$ during pyrolysis in various $\mathrm{NH}_{3}$ concentrations. Solid lines and symbols are the NH peak values and the dashed lines and hollow symbols are the $\mathrm{NH}_{2}$ values. Circles: $0.001\left[\mathrm{NH}_{3}\right]$; triangles: $0.003\left[\mathrm{NH}_{3}\right]$; and squares: $0.008 / 0.001\left[\mathrm{NH}_{3}\right]$. Times indicated for the $0.5 \mathrm{~atm}$ experiments (shown here as hollow diamonds) are the experimental values divided by two.

constant pressure) [31]. The equilibrium products $\mathrm{H}_{2}$ and $\mathrm{N}_{2}$ exceed the reactant concentrations after $400 \mu \mathrm{sec}$. The important intermediaries $\mathrm{NH}_{2}$, $\mathrm{H}, \mathrm{NH}$, and $\mathrm{N}$ rapidly form in that sequence. $\mathrm{NH}_{2}$ disappears rapidly, while $\mathrm{NH}$ disappears slowly. The rapidly-turned-over species, $\mathrm{N}_{2} \mathrm{H}_{2}$ and $\mathrm{NNH}$, never reach $1 \mathrm{ppm}$ but are the major route for the formation of $\mathrm{N}_{2}$. The heavier products $\mathrm{N}_{2} \mathrm{H}_{3}$ and $\mathrm{N}_{2} \mathrm{H}_{4}$ form in insignificant amounts and do not affect the modelled profiles of the measured species.

\section{Contribution and Sensitivity Analysis}

The contribution factors for the species $\mathrm{NH}_{2}$ and $\mathrm{NH}$ are shown in Figures 8 and 9 . The contribution factor is the net production (or loss) rate of a species due to a particular reaction.

The two major loss reactions for $\mathrm{NH}_{3}$ are also the primary production paths for $\mathrm{NH}_{2}$. It can be assumed that the alternate route of reaction (1a), $\mathrm{NH}_{3}+\mathrm{M} \rightarrow \mathrm{NH}+\mathrm{H}_{2}$, is insignificant compared to the primary route $[1,3]$. The primary loss reactions for $\mathrm{NH}_{2}$ result from collisions with $\mathrm{H}$, $\mathrm{NH}$, and $\mathrm{NH}_{2}$.

The primary production of $\mathrm{NH}$ is from reaction (9), $\mathrm{NH}_{2}+\mathrm{H} \rightarrow \mathrm{NH}+$ $\mathrm{H}_{2}$, and from reaction (12), $\mathrm{NH}_{2}+\mathrm{NH}_{2} \rightarrow \mathrm{NH}+\mathrm{NH}_{3}$. The loss routes for $\mathrm{NH}$ are reactions with $\mathrm{H}, \mathrm{NH}$, and $\mathrm{NH}_{2}$. These loss rates are effectively gas kinetic with no strong temperature dependence. Reactions (9) and (11) 
TABLE I. Ammonia pyrolysis mechanism.

\begin{tabular}{|c|c|c|c|c|c|c|}
\hline$\#$ & REACTIONS & $\Delta \mathrm{H}_{298}^{\circ}$ & A & $b$ & $\mathrm{E}_{\mathrm{A}}$ & Ref. \\
\hline 1 & $\mathrm{NH}_{3}+\mathrm{M}=\mathrm{NH}_{2}+\mathrm{H}+\mathrm{M}$ & 108.52 & $2.20 \mathrm{E} 16$ & 0.0 & 93468 & $*$ \\
\hline 2 & $\mathrm{NH}_{3}+\mathrm{H}=\mathrm{NH}_{2}+\mathrm{H}_{2}$ & 4.45 & $6.36 \mathrm{E} 05$ & 2.39 & 10171 & 5 \\
\hline 3 & $\mathrm{H}_{2}+\mathrm{M}=\mathrm{H}+\mathrm{H}+\mathrm{M}$ & 104.14 & $2.19 \mathrm{E} 14$ & 0.0 & 95970 & 38 \\
\hline 4 & $\mathrm{NH}+\mathrm{M}=\mathrm{N}+\mathrm{H}+\mathrm{M}$ & 79.80 & $2.65 \mathrm{E}] 4$ & 0.0 & 75500 & 9 \\
\hline 5 & $\mathrm{NH}+\mathrm{H}=\mathrm{H}_{2}+\mathrm{N}$ & -24.34 & $3: 60 \mathrm{E} 13$ & 0.0 & 325 & 30 \\
\hline 6 & $\mathrm{NH}+\mathrm{N}=\mathrm{N}_{2}+\mathrm{H}$ & -146.00 & $3.00 \mathrm{E} 13$ & 0.0 & (). & 12 \\
\hline 7 & $\mathrm{NH}+\mathrm{NH}=\mathrm{N}_{2}+\mathrm{H}+\mathrm{H}$ & -66.20 & $5.10 \mathrm{E} 13$ & 0.0 & 0. & 9 \\
\hline 8 & $\mathrm{NH}_{2}+\mathrm{M}=\mathrm{NH}+\mathrm{H}+\mathrm{M}$ & 91.76 & $3.16 \mathrm{E} 23$ & -2.0 & 91400 & 34 \\
\hline 9 & $\mathrm{NH}_{2}+\mathrm{H}=\mathrm{NH}+\mathrm{H}_{2}$ & -12.38 & $4.00 \mathrm{E} 13$ & 0.0 & 3650 & * \\
\hline 10 & $\mathrm{NH}_{2}+\mathrm{N}=\mathrm{N}_{2}+\mathrm{H}+\mathrm{H}$ & -54.24 & $7.20 \mathrm{E} 13$ & 0.0 & 0. & 12 \\
\hline 11 & $\mathrm{NH}_{2}+\mathrm{NH}=\mathrm{N}_{2} \mathrm{H}_{2}+\mathrm{H}$ & -27.68 & $1.50 \mathrm{E} 15$ & -0.5 & 0 & $*$ \\
\hline 12 & $\mathrm{NH}_{2}+\mathrm{NH}_{2}=\mathrm{NH}_{3}+\mathrm{NH}$ & -16.76 & $5.00 \mathrm{E} 13$ & 0.0 & 100000 & * \\
\hline 13 & $\mathrm{NH}_{2}+\mathrm{NH}_{2}=\mathrm{N}_{2} \mathrm{H}_{2}+\mathrm{H}_{2}$ & -40.06 & $5.00 \mathrm{E} 11$ & 0.0 & 0 . & 12 \\
\hline 14 & $\mathrm{NNH}+\mathrm{M}=\mathrm{N}_{2}+\mathrm{H}+\mathrm{M}$ & -6.47 & $2.00 \mathrm{E} 14$ & 0.0 & 20000 & 12 \\
\hline 15 & $\mathrm{NNH}+\mathrm{H}=\mathrm{N}_{2}+\mathrm{H}_{2}$ & -110.61 & $4.00 \mathrm{E} 13$ & 0.0 & 3000 & 34 \\
\hline 16 & $\mathrm{NNH}+\mathrm{NH}=\mathrm{N}_{2}+\mathrm{NH}_{2}$ & -98.23 & $5.00 \mathrm{E} 13$ & 0.0 & 0. & 12 \\
\hline 17 & $\mathrm{NNH}+\mathrm{NH}_{2}=\mathrm{N}_{2}+\mathrm{NH}_{3}$ & -114.99 & $500 \mathrm{E} \perp 3$ & 0.0 & 0 & 12 \\
\hline 18 & $\mathrm{~N}_{2} \mathrm{H}_{2}+\mathrm{M}=\mathrm{NNH}+\mathrm{H}+\mathrm{M}$ & 59.71 & $5.00 \mathrm{E} 16$ & 0.0 & 50000 & 12 \\
\hline 19 & $\mathrm{~N}_{2} \mathrm{H}_{2}+\mathrm{H}=\mathrm{NNH}+\mathrm{H}_{2}$ & -44.43 & $5.00 \mathrm{E} 13$ & 0.0 & 1000 & 12 \\
\hline 26 & $\mathrm{~N}_{2} \mathrm{H}_{2}+\mathrm{NH}=\mathrm{NNH}+\mathrm{NH}_{2}$ & -32.05 & $1.00 \mathrm{E} \mid 3$ & 0.0 & 1000 & 12 \\
\hline 21 & $\mathrm{~N}_{2} \mathrm{H}_{2}+\mathrm{NH}_{2}=\mathrm{NNH}+\mathrm{NH}_{3}$ & -48.81 & $1.00 \mathrm{E} 1.3$ & 0.0 & 1000 & 12 \\
\hline
\end{tabular}

The rate coefficients are expressed as $A T^{b} \exp \left(-E_{A} / R T\right)\left[\mathrm{cm}^{3} \mathrm{~mol}^{-1} \mathrm{~s}^{-1}\right]$. The heats of formation are in units of $\mathrm{kcal} / \mathrm{mol}^{-1}$. The activation energies are in units of $\mathrm{cal} \mathrm{mol}^{-1}$. $*$ indicates that the rate coefficient is determined in this work.

have similar shaped contribution plots and experimentally it is difficult to distinguish their component contribution to the $\mathrm{NH}$ profile.

The sensitivity coefficient is defined as [32]

$$
X_{i j}(t)=A_{j} / X_{i}^{\max }\left(d X_{i} / d A_{j}\right)(t)
$$

where $X_{i j}(t)$ is the sensitivity coefficient for a change in the mol fraction of the $i$ th species due to a small change in the temperature independent factor in the $j$ th reaction rate coefficient $A_{j}$, and $X_{i}^{\max }$ indicates the maximum value of $X_{i}$ that occurred in the calculated profile.

The sensitivity plots for $\mathrm{NH}_{2}$ and $\mathrm{NH}$ are shown in Figures 10 and 11. Only reactions that yield greater than $10 \%$ of the sensitivity of the largest reaction are shown. The sensitivity analysis computation has been per- 


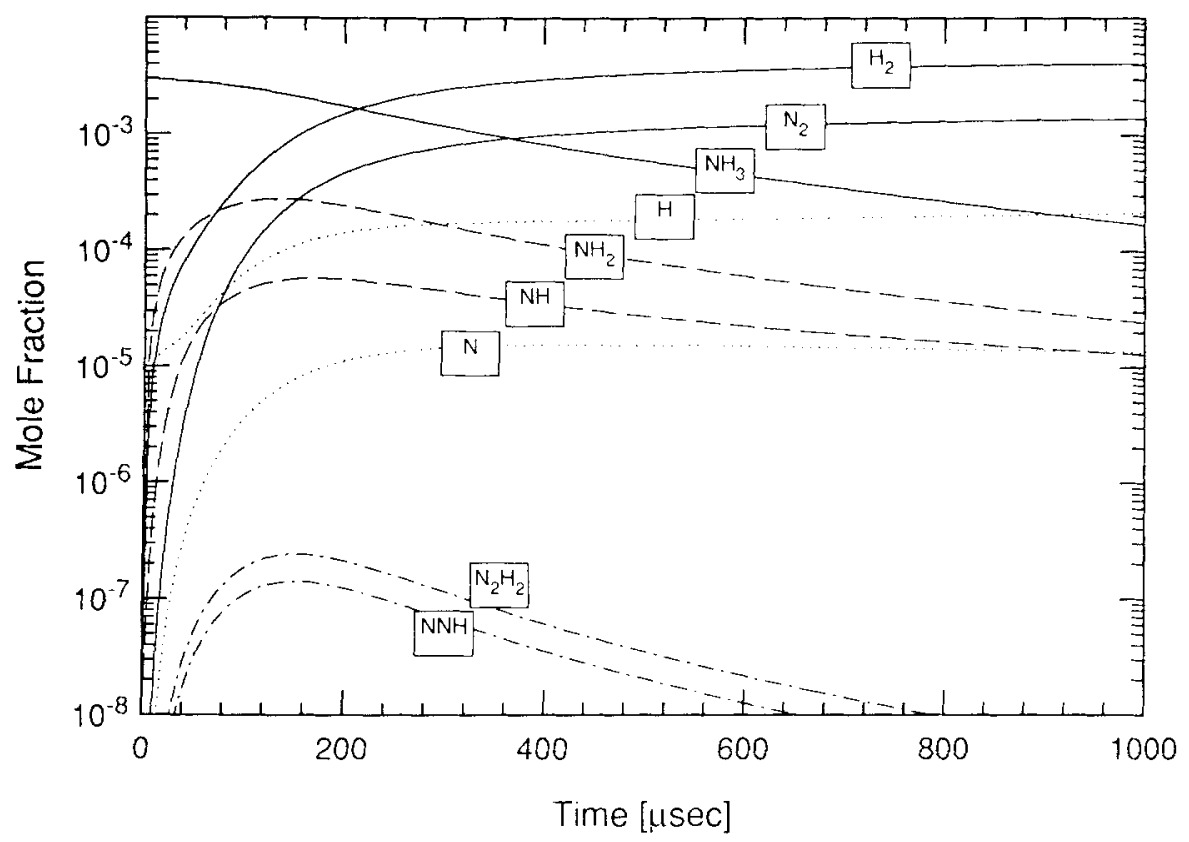

Figure 7. Mol fraction time-histories for all major species in pyrolysis kinetic model. Modelled shock conditions are $T=2500 \mathrm{~K}$, and $P=1.00 \mathrm{~atm}\left[\mathrm{NH}_{3}\right]=0.003 . \mathrm{N}_{2} \mathrm{H}_{3}$ and $\mathrm{N}_{2} \mathrm{H}_{4}$ exist in concentrations at or below $10^{-9}$.

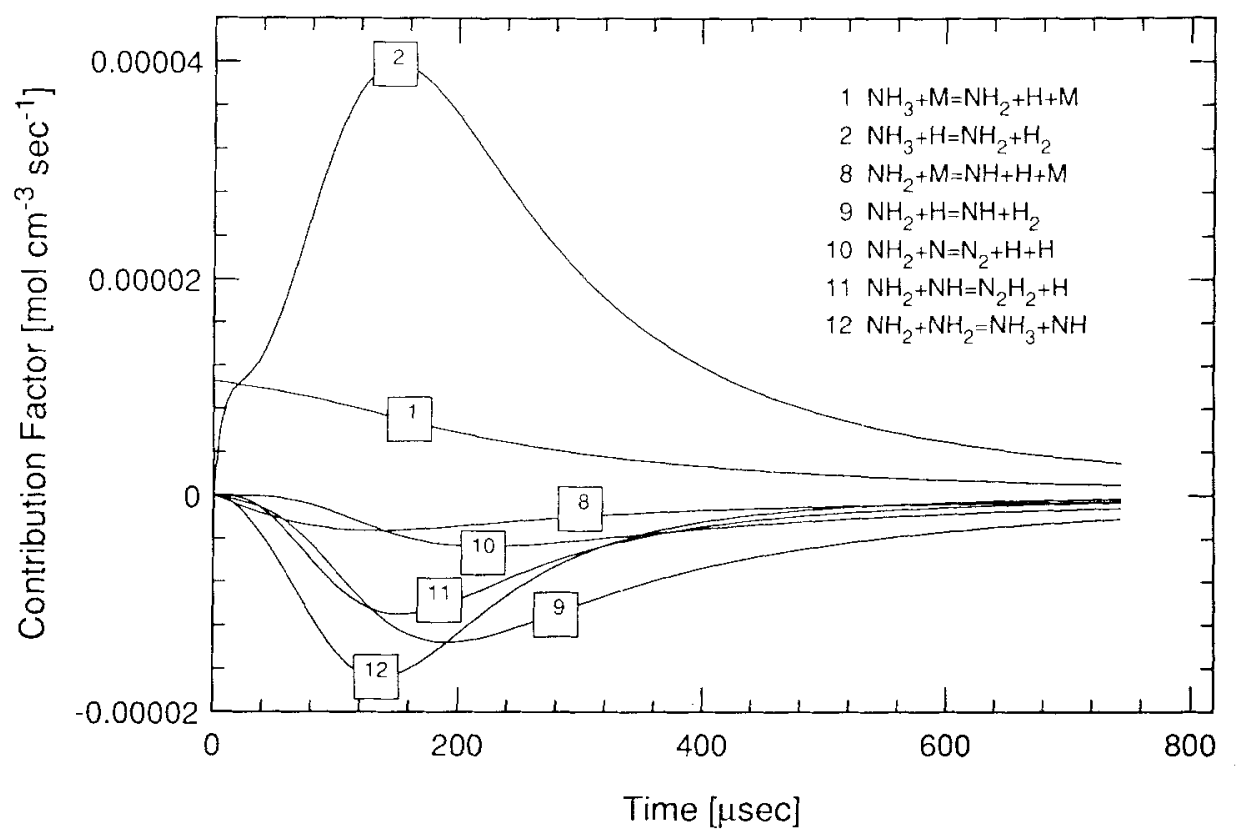

Figure 8. $\mathrm{NH}_{2}$ reactions contributions. Only reactions whose values are $10 \%$ or more of the largest contributor are included. Model conditions are the same for Figure 7. 


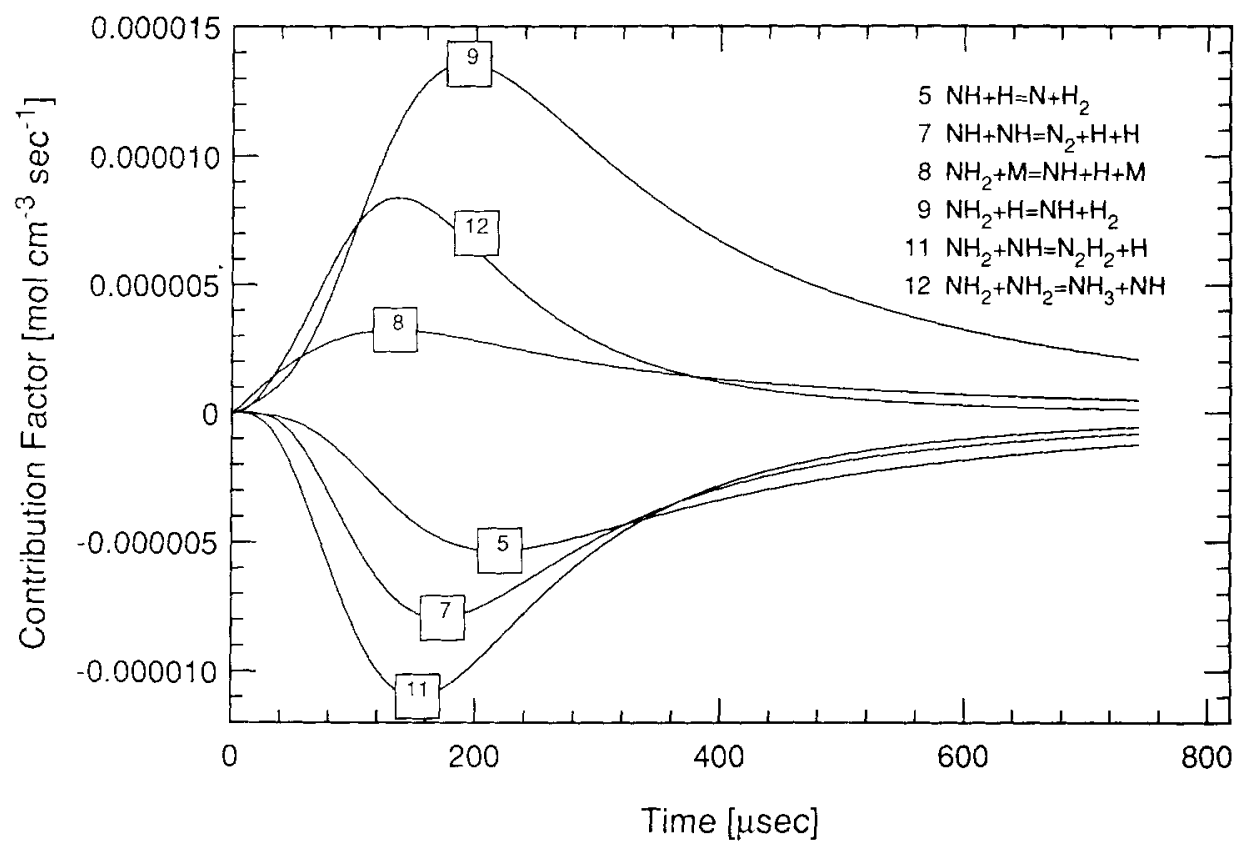

Figure 9. NH reaction contributions. Only reactions whose values are $10 \%$ or more of the largest contributor are included. Model conditions are the same for Figure 7.

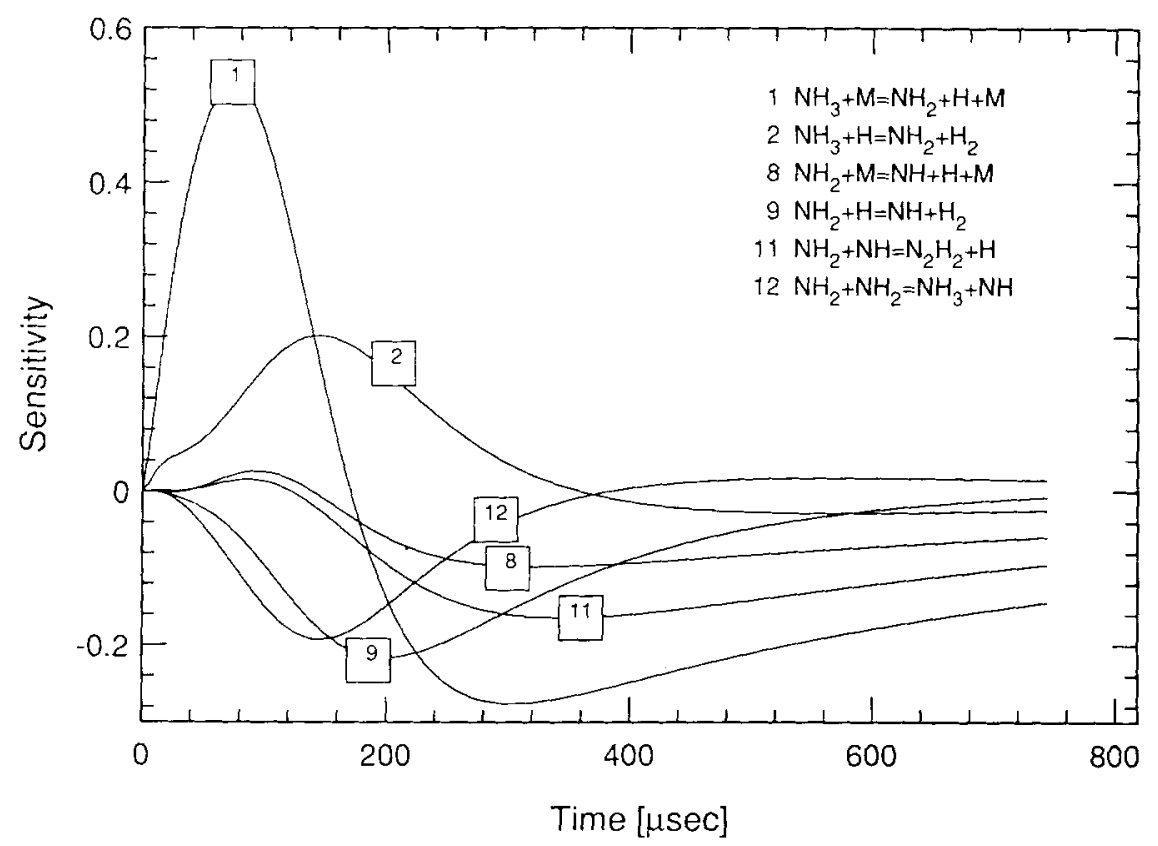

Figure 10. $\mathrm{NH}_{2}$ sensitivity analysis. Only reactions whose sensitivity coefficient values are $10 \%$ or more of the most sensitive are included. Model conditions are the same as for Figure 7. 


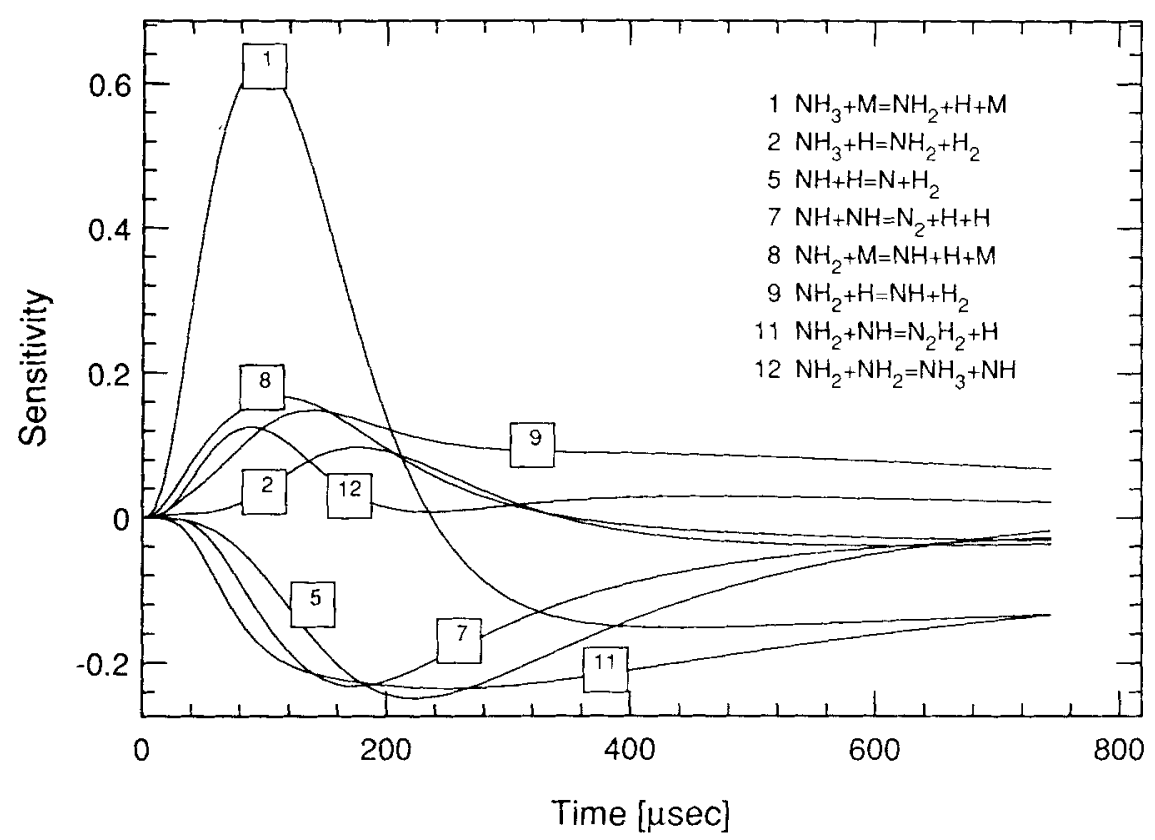

Figure 11. NH sensitivity analysis. Only reactions whose sensitivity coefficient values are $10 \%$ or more of the most sensitive are included. Model conditions are the same as for Figure 7.

formed using the SENKIN [32] program and a discussion of the mathematical definition for the sensitivity coefficient may be found there.

The $\mathrm{NH}_{2}$ mol fraction is most sensitive to $k_{1}$ and $k_{2}$, and somewhat less sensitive to $k_{9}$ and $k_{12}$. The $\mathrm{NH}$ mol fraction is particularly sensitive to the rate coefficient $k_{1}$. Several other minor reactions have lower and approximately equal sensitivity at various times in the decomposition.

Of the reactions that influence the time histories of $\mathrm{NH}_{2}$ and $\mathrm{NH}$, rate coefficients for reactions (8), (9), (11), and (12) have not been measured directly at high temperatures.

\section{Heats of Formation}

Andersen [27] has recently surveyed the literature on the heats of formation of $\mathrm{NH}$ and $\mathrm{NH}_{2}$, and his recommended values are very close to the values in the Sandia Database which are used in this study [32]. The Sandia Database is similar to the JANAF data for all species except $\mathrm{NH}$ and NNH. $\mathrm{H}^{\circ}(298)$ for $\mathrm{NH}_{2}$ is $45.50 \mathrm{kcal} \mathrm{mol}^{-1} ; \mathrm{H}^{\circ}(298)$ for $\mathrm{NH}$ is $85.20 \mathrm{kcal} \mathrm{mol}^{-1}$. One consequence of the uncertainty in the knowledge of the heats of formation for $\mathrm{N} / \mathrm{H}$ species is its effect on the uncertainty of the modelled $\mathrm{NH}$ profiles. Andersen gives an uncertainty of $\pm 0.5 \mathrm{kcal} \mathrm{mol}^{-1}$ for $\mathrm{H}^{\circ}(298)$ for $\mathrm{NH}$. This gives an added $\pm 10 \%$ uncertainty in $k_{5},\left(\mathrm{H}+\mathrm{NH} \rightarrow \mathrm{N}+\mathrm{H}_{2}\right)$, one of the dominant loss mechanisms of $\mathrm{NH}$, as this rate was originally measured in the reverse direction [30]. 


\section{Discussion}

In this section, the rate coefficients of four reactions are discussed. The new determination of the rate coefficient for reaction (1), $\mathrm{NH}_{3}+\mathrm{M}=$ $\mathrm{NH}_{2}+\mathrm{H}+\mathrm{M}$, is based on a re-analysis of four previous studies. The determination of the three rate coefficients, of reactions (9), (11), and (12), are based on a comparison of the experimentally determined $\mathrm{NH}$ and $\mathrm{NH}_{2}$ profiles with that of the modelled profiles. All rate coefficients given in this article are in units of $\mathrm{cm}^{3} \mathrm{~mol}^{-1} \mathrm{~s}^{-1}$ with activation energies in cal $\mathrm{mol}^{-1}$.

$$
\mathrm{NH}_{3}+\mathrm{M}=\mathrm{NH}_{2}+\mathrm{H}+\mathbf{M}
$$

The low pressure limit of this reaction has been reviewed by Hanson and Salimian [34]. They give a value of the rate coefficient of $2.51 \times$ $10^{16} \exp (-93790 / \mathrm{RT})( \pm 35 \%)$ derived from work by Roose [1]. Three other primary references for this rate, Yumura and Asaba [4], Holtzrichter and Wagner [3], and Dove and Nip [2] differ in varying degrees from Roose's value. All four of these works were done before Michael, Sutherland, and Klemm's improved determination of $k_{2}$ in 1985 [5]. We have found that it is possible to reconcile these four works and achieve smaller overall uncertainty if the newer value for the rate coefficient of reaction (2), $\mathrm{NH}_{3}+$ $\mathrm{H} \rightarrow \mathrm{NH}_{2}+\mathrm{H}$, is used in a reanalysis of these studies.

The method used by all four groups was to derive the rate coefficient from the early time behavior of one of $\mathrm{NH}_{3}, \mathrm{NH}_{2}$, or $\mathrm{H}$, in dilute mixtures of $\mathrm{NH}_{3}$ in argon (krypton in the case of Dove and Nip). The slope derived from the initial rate (of formation or of loss) can be simply corrected (to first order) to allow for the contribution of the competing reaction (2). For the three experiments measuring $\mathrm{NH}_{3}$ or $\mathrm{NH}_{2}$ concentrations, this correction lowers the rate coefficient, and for those of Yumura and Asaba measuring $\mathrm{H}$, it increases the rate coefficient. The correction is based on values which are given in each article of the typical time used to determine the slope, the typical concentration of $\mathrm{NH}_{3}$, the rate coefficients employed for $\mathrm{NH}_{3}+\mathrm{H}$, and the temperature. The rate coefficient correction is of the form

$$
k_{1 \text { corr }}=k_{1 \text { uncorr }} /\left(1 \pm \Delta k_{2}\left[\mathrm{NH}_{3}\right] \Delta t\right)
$$

where the plus sign is used for $\mathrm{NH}_{3}$ and $\mathrm{NH}_{2}$ measurements and the minus sign is used in the case of $\mathrm{H}$ atom measurements.

Using this procedure and the published conditions of the measurements, the rate coefficients of all four studies have been adjusted and are found to be within $\pm 15 \%$ of the rate coefficient derived in Roose's work. This corrected value is $2.20 \times 10^{16} \exp (-93470 / R T)$. The original and corrected values are shown in Figure 12.

Holzrichter and Wagner [2] discuss the role of reaction (1a), $\mathrm{NH}_{3}+\mathrm{M}=$ $\mathrm{NH}+\mathrm{H}_{2}+\mathrm{M}$, but argue that it is not significant in the decomposition of $\mathrm{NH}_{3}$ based on the early time emission of $\mathrm{NH}$. Roose, based on a similar emission experiment, gives as an upper limit to this rate coefficient a value of $6.3 \times 10^{14} \exp (-93390 / R T)$, at least $40 X$ less than the dominant channel. 


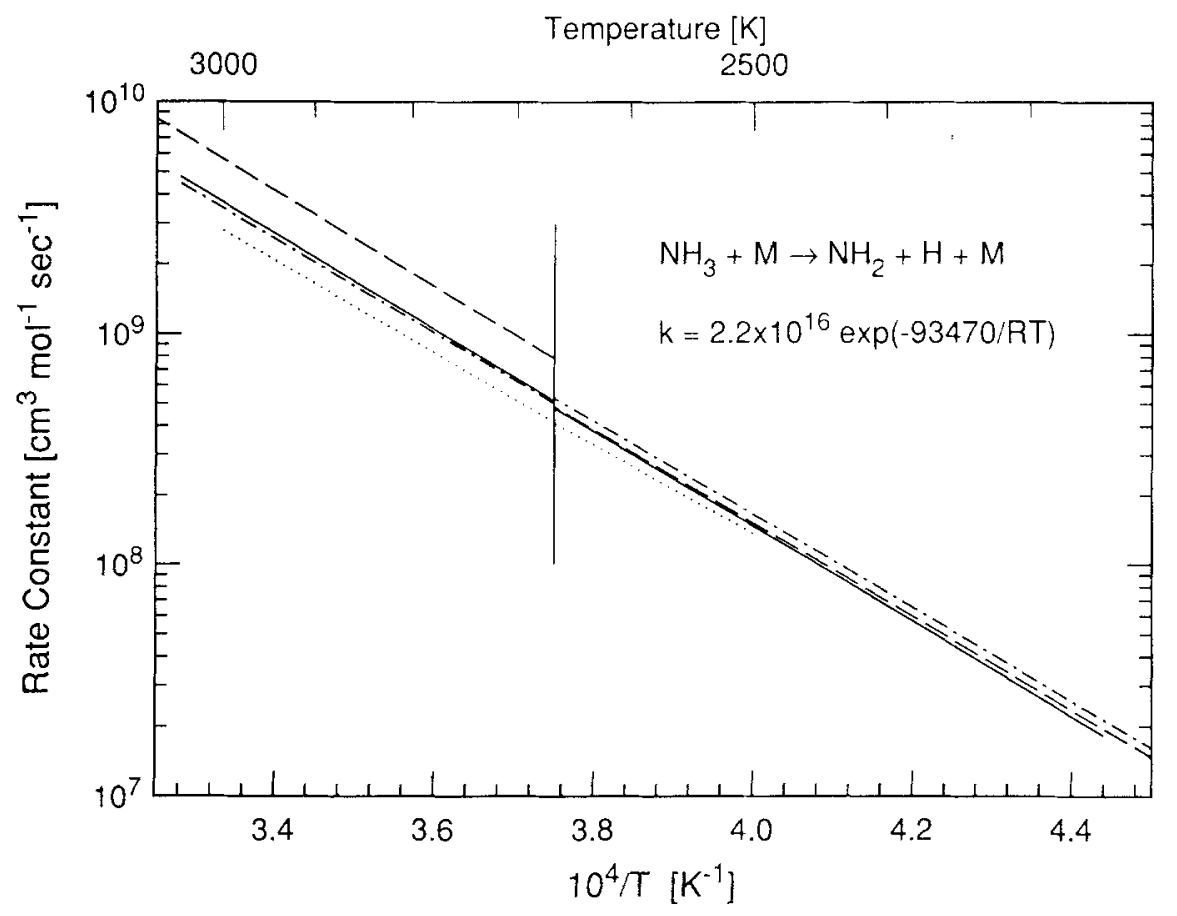

Figure 12. Arrhenius plot for reaction (1): $\mathrm{NH}_{3}+\mathrm{M} \rightarrow \mathrm{NH}_{2}+\mathrm{H}+\mathrm{M}$. Solid line: Roose [1]; dotted line: Dove and Nip [2]; dashed line: Holzrichter and Wagner [3]; and dot-dashed line: Yumura and Asaba [4]. Original results shown above $2650 \mathrm{~K}$, corrected values of the rate coefficient shown below $2650 \mathrm{~K}$.

$$
\mathrm{NH}_{2}+\mathrm{H}=\mathrm{NH}+\mathrm{H}_{2}
$$

We have found only five published determinations of $k_{9}$; four from experiment and one from a theoretical estimate. These are shown in Figure 13.

Roose [1] has used $\mathrm{NH}$ emission in $\mathrm{NH}_{3}$ pyrolysis at $2800 \mathrm{~K}$ and has obtained a value of $3.9 \times 10^{13}$. His suggested extrapolation of this rate coefficient to lower temperatures is $6.92 \times 10^{13} \exp (-3650 / R T)$. Miller [12-16] have used the rate coefficient of Roose successfully for modelling of flames. As well, they have found that the use of the temperature dependence for this reaction suggested by Yumura and Asaba results in drastic changes in flame profiles and have degraded the agreement between these model predictions and experiment.

In shock tube ammonia pyrolysis experiments in the temperature range 2600 to $2800 \mathrm{~K}$, Dove and Nip [2] have studied the reverse reaction and have obtained $k_{-9}=2 \times 10^{12}$. At $2700 \mathrm{~K}$ this is equivalent to $k_{9}=2.88 \times 10^{13}$.

Yumura and Asaba [26] have studied reaction (9) in hydrazine shock tube experiments in the temperature range 2230 to $3460 \mathrm{~K}$ and give $k_{9}=$ $4.47 \times 10^{13} \exp (-10440 / R T)$. They provide additional discussion of this reaction in their $\mathrm{NH}_{3}$ pyrolysis study [4].

Dean, Lyon, and Hardy [21] have found that a rate two times that found in Bahn [35] gave satisfactory fits to their flame data. Bahn [35] lists a theoretical estimate of this rate coefficient from the work of Mayer [36,37]. The value of Mayer is $k_{9}=5 \times 10^{11} T^{0.5} \exp (-2000 / R T)$. 


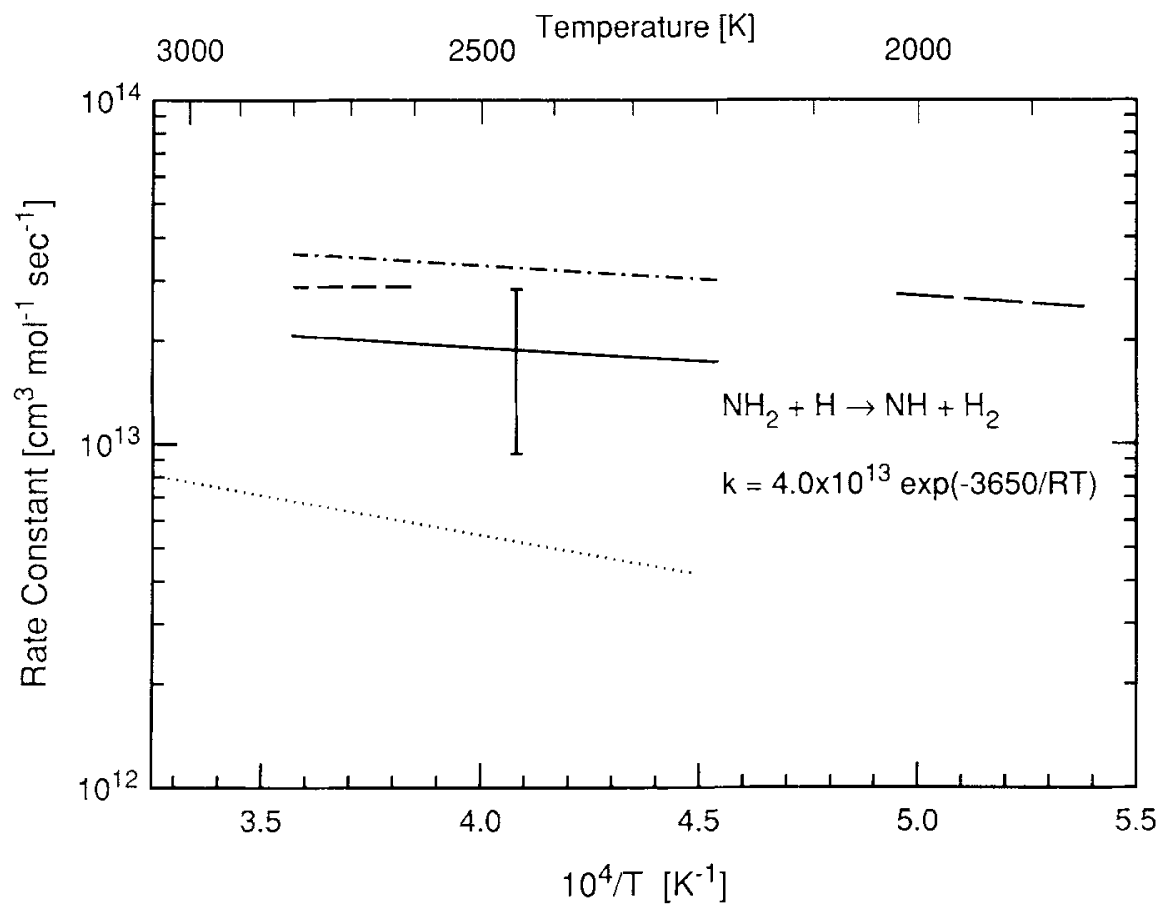

Figure 13. Arrhenius plot for reaction (9): $\mathrm{NH}_{2}+\mathrm{H}=\mathrm{NH}+\mathrm{H}_{2}$. Solid line: present work, $\pm 50 \%$ error bar; dashed line: Dove and Nip [2]; dot-dashed line: Roose [1]; dotted line: Yumura and Asaba [26]; and long-dashed line: Dean, Chou, and Stern [21].

Our determination of this rate coefficient is closely related to the selection of the rate coefficient for reaction (11): $\mathrm{NH}+\mathrm{NH}_{2} \rightarrow \mathrm{N}_{2} \mathrm{H}_{2}+\mathrm{H}$. The shapes of their contribution factors are similar in $\mathrm{NH}_{3}$ pyrolysis experiments and, because of this subtlety, it is necessary to fit both $\mathrm{NH}$ and $\mathrm{NH}_{2}$ over a large range of conditions to place constraints on these rate coefficients. The $\mathrm{NH}_{2}$ data has been fit to the decay region in the temperature range 2200 to $2800 \mathrm{~K}$. The $\mathrm{NH}$ data has been fitted over both the rise and the fall.

We find the best fit is given by $k_{9}=4 \times 10^{13} \exp (-3650 / R T)( \pm 50 \%)$. Efforts to closely represent the database with values beyond $\pm 50 \%$ of this rate coefficient require unrealistic values for $k_{11}$ or $k_{12}$. Examples of the effect on the $\mathrm{NH}$ and $\mathrm{NH}_{2}$ profiles in this model by varying this rate coefficient by $\pm 50 \%$ are shown in Figure 14. The data do not allow a temperature dependence to be determined, and the activation energy of Roose is used. The activation energy of Roose is based on a two parameter fit to the estimate of Mayer. The best fit value to our database is in agreement with Dove and Nip [2] and the theoretical estimate of Mayer [36,37].

$$
\mathrm{NH}+\mathrm{NH}_{2}=\mathrm{N}_{2} \mathrm{H}_{2}+\mathrm{H}
$$

The rate coefficient for this reaction at high temperatures has previously only been estimated. Miller [14] state that this reaction can be compared to the isoelectric reactions $\mathrm{NH}+\mathrm{OH} \rightarrow \mathrm{HNO}+\mathrm{H}$ for which they give $k=2 \times 10^{13}$, and $\mathrm{O}+\mathrm{NH}_{2} \rightarrow \mathrm{HNO}+\mathrm{H}$ which they give as $k=6.63 \times$ 


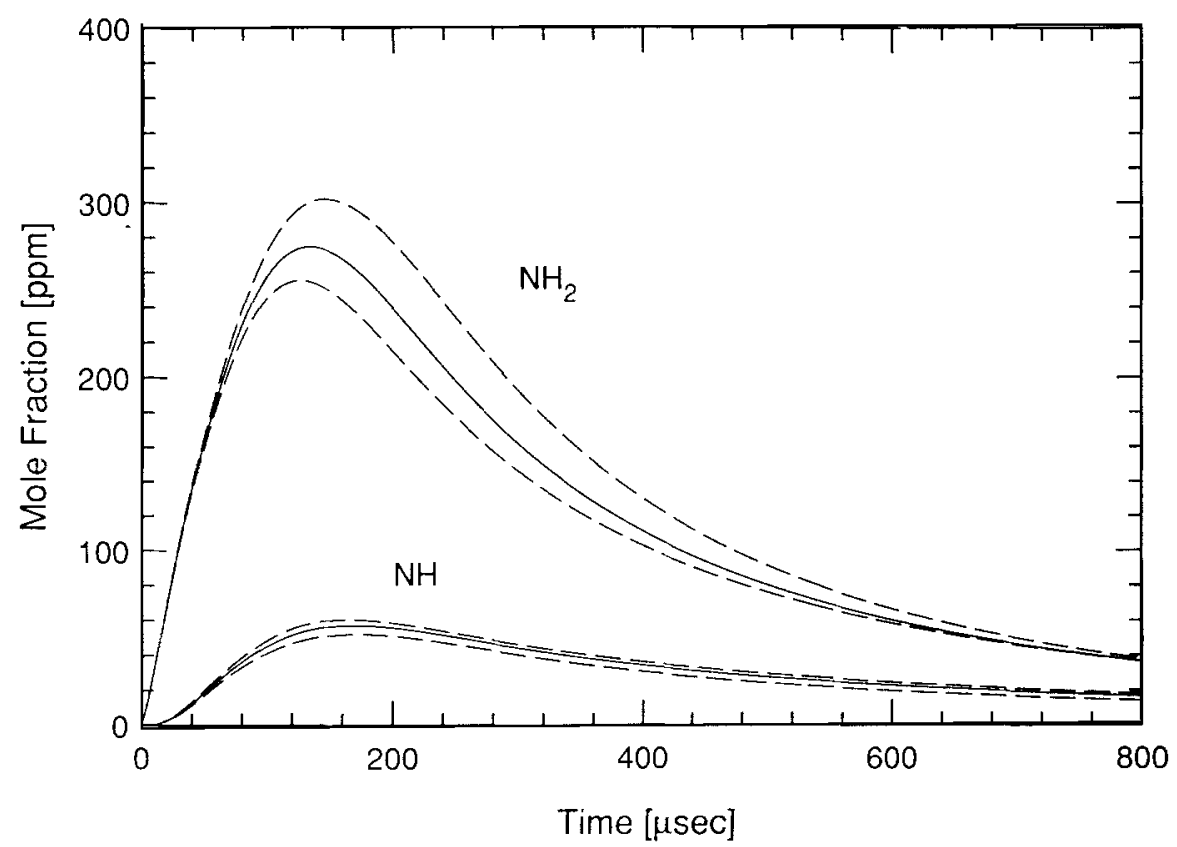

Figure 14. Influence of varying reaction (9) in the kinetic model. Solid line: rate coefficient found in Table $I$ and dashed lines: $\pm 50 \%$ variation. Model conditions as in Figure 7.

$10^{14} T^{-0.5}$. They expect a $T^{-0.5}$ temperature dependence for radical-radical reactions with no rearrangement. Miller use $k_{11}=5 \times 10^{13}$ at $1200 \mathrm{~K}$ and they rank this reaction as important in the study of the oxidation of ammonia in flames [14]. Hanson and Salimian [18] give as an estimate $3.16 \times 10^{13}$ in their study of $\mathrm{NH}_{3}$ and NO. As well, they state that this reaction is part of a path that replenishes $\mathrm{H}$ and produces $\mathrm{N}_{2}$ through a path not including NO. Dean, Chou, and Stern [21] give as a rate coefficient $5 \times 10^{13}$, while Cohen [17] gives as an estimate $3.16 \times 10^{13}$, Dransfeld [23] have measured this rate coefficient at room temperature as $8( \pm 3) \times 10^{13}$. They discuss the four possible product routes and give a preference to this channel at lower temperatures.

The fitting procedure for this reaction is similar to that of reaction (9). The best fit to our database is $k_{11}=1.5 \times 10^{15} T^{-0.5}( \pm 50 \%)$. At $2500 \mathrm{~K}$, $k_{11}=3.0 \times 10^{13}$. Examples of the variation of this rate coefficient on the modelled calculations for concentration are shown in Figure 15. The recent determinations of the other dominant $\mathrm{NH}$ loss paths reaction $(-5)$ [9], $\mathrm{H}+$ $\mathrm{NH}=\mathrm{N}+\mathrm{H}_{2}$, and reaction (7) [30], $\mathrm{NH}+\mathrm{NH}=\mathrm{N}_{2}+\mathrm{H}+\mathrm{H}$, allows us to reduce our uncertainty in this loss path. The use of the $T^{-0.5}$ temperature dependence and the room temperature rate coefficient of Dransfeld gives good agreement with our fitted rate coefficient as well as the intermediate temperature regime rate coefficient used by Miller.

$$
\mathrm{NH}_{2}+\mathrm{NH}_{2}=\mathrm{NH}+\mathrm{NH}_{3}
$$

The contribution factors shown in Figure 8 indicate that this reaction significantly influences the rise time of the $\mathrm{NH}$ data. Without a large con- 


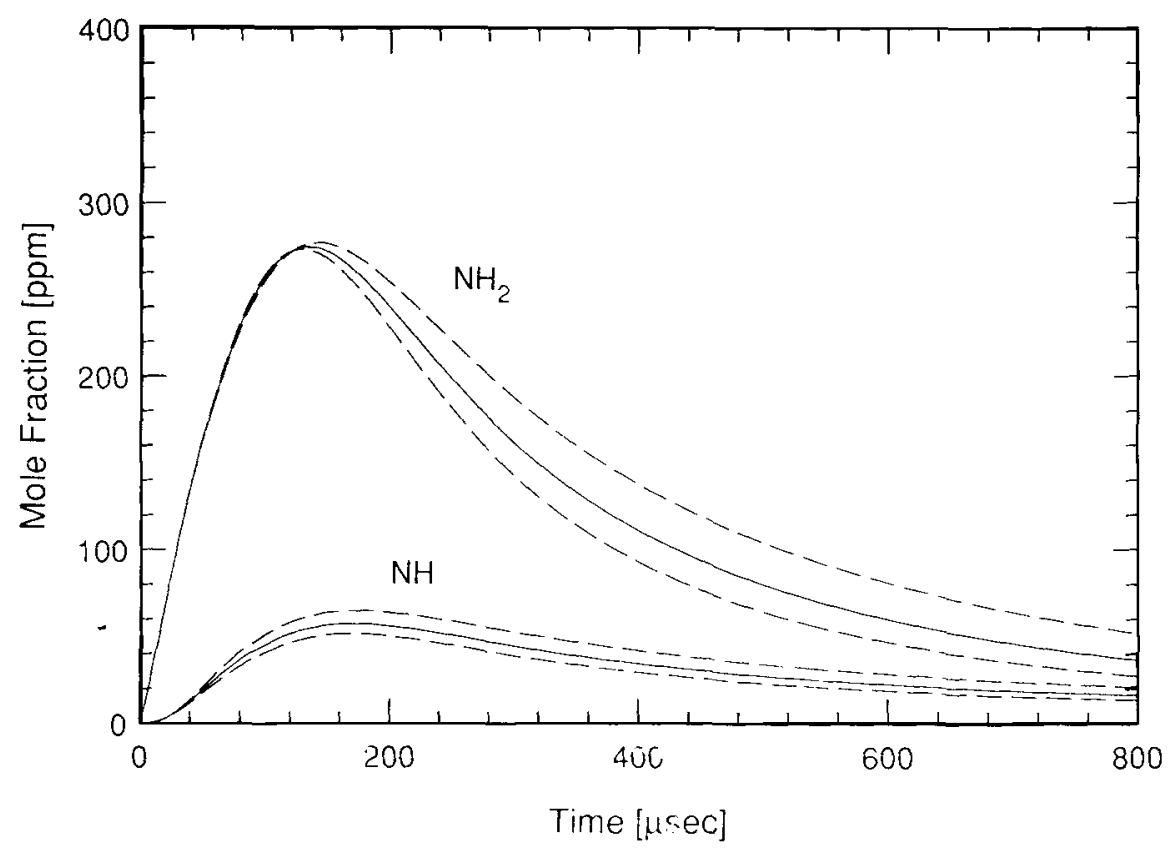

Figure 15. Influence of varying reaction (11) in the kinetic model. Solid line: rate coefficient found in Table I and dashed lines: $\pm 50 \%$ variation. Model conditions as in Figure 7.

tribution by this reaction to the NH profiles, the model predictions of concentrations at early times would fall well below the experimental results.

It is not possible to explain the required rate of $\mathrm{NH}$ formation through the use of a large value of $k_{8}\left(\mathrm{NH}_{2}+\mathrm{M} \rightarrow \mathrm{NH}+\mathrm{H}+\mathrm{M}\right)$ and maintain the correct shape of the $\mathrm{NH}$ profile. A 10 fold increase in $k_{8}$ gives no improvement in fitting the rise time in the low temperature $\mathrm{NH}$ data and produces an anomalous peak shape to the concentration profile. It is also not possible to explain this early time behavior using an enlarged value of the rate coefficient of reaction (1a), $\mathrm{NH}_{3}+\mathrm{M} \rightarrow \mathrm{NH}+\mathrm{H}_{2}$.

Various workers estimate values for $k_{12}$ which range over an order of magnitude. Cohen [17] suggests $10^{8} T^{1.5}$ and states that this route is likely to be important and can be estimated by comparison with the $\mathrm{OH}$ disproportionation rate. An extrapolation of his rate coefficient to room temperature is much higher than that given by Dransfeld [23] (less than $2 \times 10^{9}$ ). Miller [12] uses $5 \times 10^{12} \exp (-10000 / R T)$ and Roose [1] uses $6.3 \times$ $10^{12} \exp (-10000 / R T)$. Both are in agreement with Dransfeld. Bahn [35] gives $2 \times 10^{11} T^{0.623} \exp (-1810 / R T)$ in agreement with Cohen.

The best fit to our database is given by $k_{12}=5 \times 10^{13} \exp (-10000 / R T)$ ( $\pm 50 \%$ ). At $\mathrm{NH}_{3}$ pyrolysis temperatures, the temperature dependence of Miller and Roose $\left(E_{A}=10000 \mathrm{cal} \mathrm{mol}^{-1}\right)$ is similar to that given by Cohen [17], yet allows for a rate coefficient that agrees with the room temperature value of Dransfeld. This present determination supports the suggestion by Cohen and Bahn of a large high temperature value of $k_{12}$. Examples showing the effect of the variation of this rate coefficient on the modelled profiles of $\mathrm{NH}$ and $\mathrm{NH}_{2}$ are shown in Figure 16. 


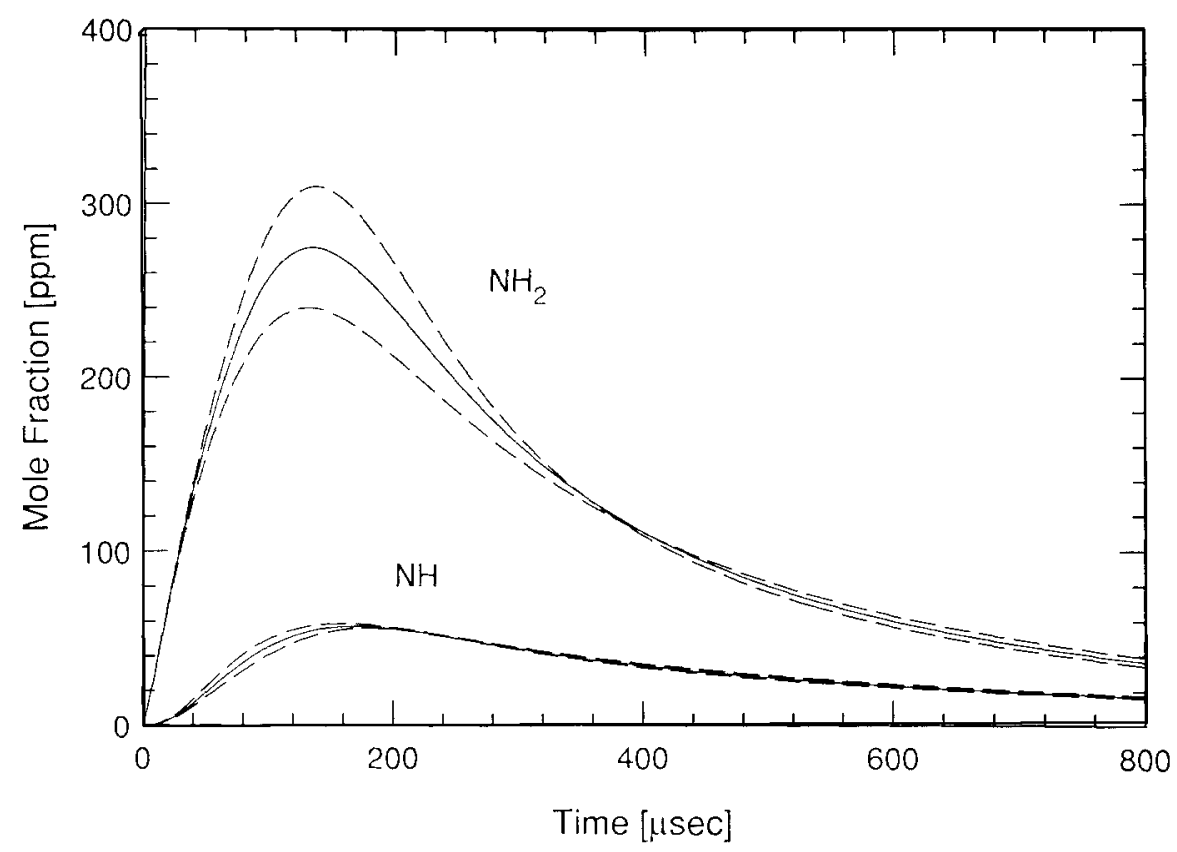

Figure 16. Influence of varying reaction (12) in the kinetic model. Solid line: rate coefficient found in Table I and dashed lines: $\pm 50 \%$ variation. Model conditions as in Figure 7.

We were unable to infer the magnitude of any other product channels of the reaction, $\mathrm{NH}_{2}+\mathrm{NH}_{2} \rightarrow$ products. Representative estimates of the rate coefficients of the various branch channels are shown in the Arrhenius diagram in Figure 17. The branch reactions which form product species with $\mathrm{N}-\mathrm{N}$ bonds $\left(\mathrm{N}_{2} \mathrm{H}_{2}+\mathrm{H}_{2}, \mathrm{~N}_{2} \mathrm{H}_{3}+\mathrm{H}\right.$, and $\left.\mathrm{N}_{2} \mathrm{H}_{4}\right)$ are generally predicted to be much slower than reaction (12). As well, these branch reactions only slightly affect the $\mathrm{H}$-atom and the $\mathrm{NH}$ profiles in our mechanism. Estimates of the rate coefficients for the branches which form $\mathrm{N}_{2} \mathrm{H}_{4}$ or $\mathrm{N}_{2} \mathrm{H}_{3}+\mathrm{H}$ are given by Dean [21]. Inclusion of a submechanism in the modelling which included these branch reactions did not significantly affect the fitted values of the rate coefficients of Reactions (9), (11), and (12).

\section{Conclusion}

An improved mechanism for the pyrolysis of $\mathrm{NH}_{3}$ has been developed. It succcessfully predicts the measured concentrations of $\mathrm{NH}$ and $\mathrm{NH}_{2}$ radicals over a wide range of reflected shock temperatures and $\mathrm{NH}_{3}$ initial concentrations.

A database of experimental risetime and peak concentrations of $\mathrm{NH}$ and $\mathrm{NH}_{2}$ is given for these pyrolysis conditions.

Constraints on the rate coefficients for the reactions $\mathrm{NH}_{2}+\mathrm{H} \rightarrow \mathrm{NH}+$ $\mathrm{H}_{2}, \mathrm{NH}_{2}+\mathrm{NH} \rightarrow \mathrm{N}_{2} \mathrm{H}_{2}+\mathrm{H}$, and $\mathrm{NH}_{2}+\mathrm{NH}_{2} \rightarrow \mathrm{NH}+\mathrm{NH}_{3}$ have been derived from the $\mathrm{NH}$ and $\mathrm{NH}_{2}$ profiles. An improved value for the rate coefficient of $\mathrm{NH}_{3}+\mathrm{M} \rightarrow \mathrm{NH}_{2}+\mathrm{H}+\mathrm{M}$ is given based on the recent accurate measurement of $\mathrm{NH}_{3}+\mathrm{H} \rightarrow \mathrm{NH}_{2}+\mathrm{H}+\mathrm{M}$. 


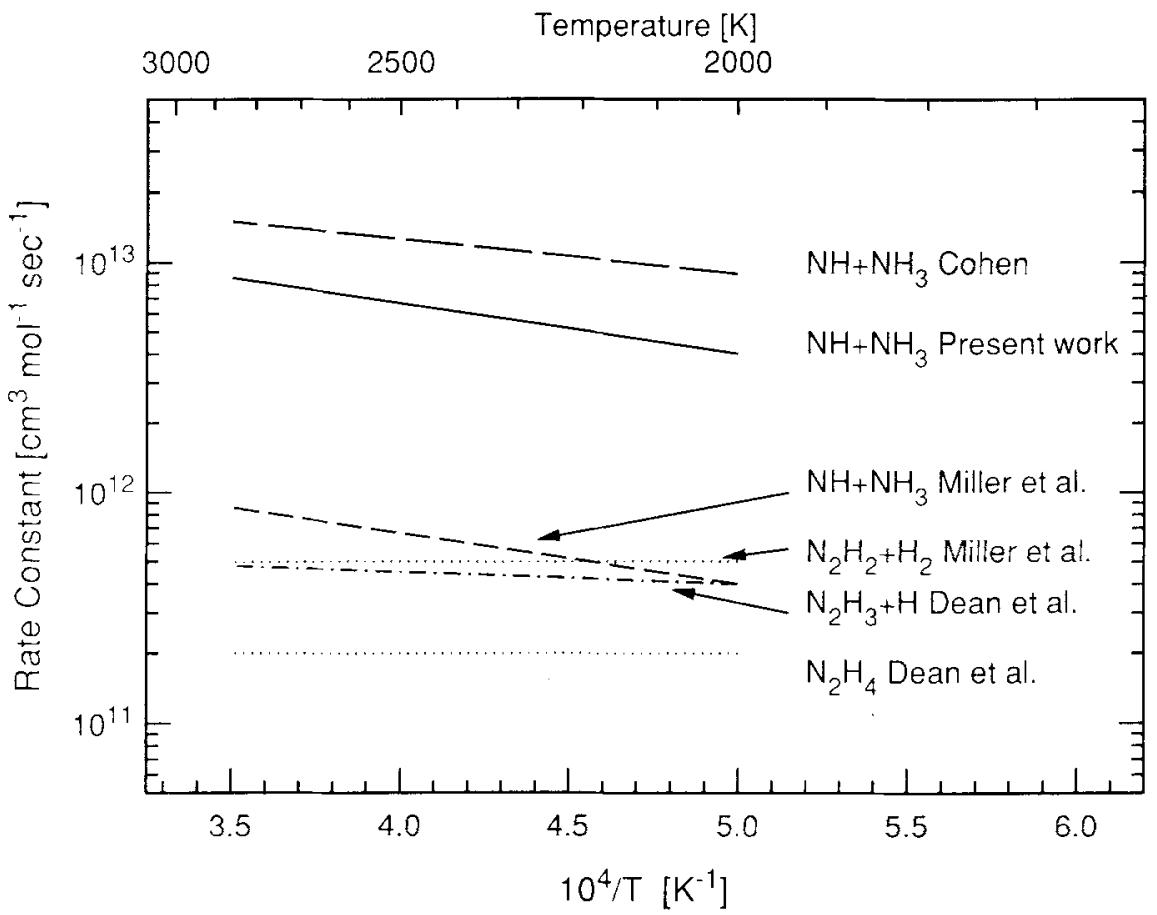

Figure 17. Arrhenius plot for the reaction: $\mathrm{NH}_{2}+\mathrm{Nh}_{2} \rightarrow$ Products. Solid line: branching product $\mathrm{NH}+\mathrm{NH}_{3}$, from the present work; long-dashed line: branching product $\mathrm{NH}+\mathrm{NH}_{3}$, from Cohen [17]; dashed line: branching product $\mathrm{NH}+\mathrm{NH}_{3}$, from Miller [12]; dot-dashed line: branching product $\mathrm{N}_{2} \mathrm{H}_{3}+\mathrm{H}$, from Dean [21]; lower dotted line: branching product $\mathrm{N}_{2} \mathrm{H}_{4}$, Dean [21]; and upper dotted line: branching product $\mathrm{N}_{2} \mathrm{H}_{2}+$ $\mathrm{H}_{2}$, from Miller [12].

\section{Acknowledgment}

This work has been supported by the Air Force Office of Scientific Research, Aerospace Sciences Directorate. One of us (KKH) was supported by the German Aerospace Research Establishment (DFVLR).

\section{APPENDIX: Kinetic rates}

Included in this listing are the majority of reactions considered in the combustion literature for ammonia pyrolysis. All rate coefficients are given in $\mathrm{cm}^{3} \mathrm{~mol}^{-1} \mathrm{~s}^{-1}$ with the activation energies in cal $\mathrm{mol}^{-1}$.

(2) $\mathbf{N H}_{3}+\mathbf{H}=\mathbf{N H}_{2}+\mathbf{H}_{2}$. This rate coefficient is now well established at temperatures below $1800 \mathrm{~K}$. A fit to a TST formulation of this rate coefficient to $2500 \mathrm{~K}$ accurate to $\pm 10 \%$ has been given by Marshall and Fontijn [7] as $6.26 \times 10^{2} T^{3.275} \exp (-8520 / R T)$. Michael, Sutherland, and Klemm [5] give a value for the temperature range of 900 to $1777 \mathrm{~K}$ of $1.82 \times$ $10^{14} \exp (-16030 / R T)$ accurate to $\pm 10 \%$. They also give a three parameter fit to all their experimental data as $6.38 \times 10^{5} T^{2.39} \exp (-10170 / R T)$. This compares well to their theoretical formulation of $6.99 \times 10^{6} T^{2.17}(-12450 / R T)$. 
We use their three parameter experimental fit. (2(a)) $\mathbf{N H}_{3}+\mathbf{N H}=$ Products. This reaction has not been mentioned in the combustion literature other than in the form of reaction (12).

(3) $\mathbf{H}_{2}+\mathbf{M}=\mathbf{H}+\mathbf{H}+\mathbf{M}(\mathbf{M}=\mathbf{A r})$. In this study, the rate coefficient affects only the $\mathrm{H}$ atom profile at long times. The value given by Baulch [38] has been used. (3(a)) $\mathbf{N}_{2}+\mathbf{M}=\mathbf{N}+\mathbf{N}+\mathbf{M}$. This reaction is insignificant when argon is used as the carrier gas.

(4) $\mathbf{N H}+\mathbf{M}=\mathbf{N}+\mathbf{H}+\mathbf{M}(\mathbf{M}=\mathbf{A r})$. Mertens [6] recently determined this rate coefficient from $\mathrm{HNCO}$ shock tube experiments and gave a value of $2.65 \times 10^{14} \exp (-75500 / R T)$ at high temperatures.

(5) $\mathbf{N H}+\mathbf{H}=\mathbf{N}+\mathbf{H}_{2}$. A recent determination of the reverse reaction rate coefficient in this laboratory gave $k_{5}=1.60 \times 10^{14} \exp (-25140 / R T)$ [30]. The equivalent forward rate coefficient, $k_{5}$, is also given as $3.2 \times$ $10^{13} \exp (-325 / R T)$. This is in good agreement with the inference for $k_{5}$ by Morley [38] of $3 \times 10^{13}$.

(6) $\mathbf{N H}+\mathbf{N}=\mathbf{H}+\mathbf{N}_{2}$. The measured profiles of this present work are not sensitive to this rate. Miller [12] estimates a rate coefficient for this reaction of $3 \times 10^{13}$. An estimate quoted by Dean [21] of $6.3 \times 10^{11} T^{0.5}$ is equivalent over our present temperature range.

(7) $\mathbf{N H}+\mathbf{N H}=\mathbf{N}_{2}+\mathbf{H}+\mathbf{H}$. The rate coefficient for this reaction has recently been measured by Mertens [9] in a study of NHCO kinetics in a shock tube. They gave a value of $5.1 \times 10^{13}$ independent of temperature over the range 2070 to $2730 \mathrm{~K}$. The products given here are in agreement with Kajimoto [39] and Miller [12]. Dean [21] use a value of $5 \times 10^{13}$ in their rich ammonia flames. (7(a)) $\mathbf{N H}+\mathbf{N H}=\mathbf{N}_{2}+\mathbf{H}_{2}$. Cohen [17] gives a value of $1 \times 10^{8} T^{1}$ for this reaction and states that this reaction and reaction (7(c)) are expected to be slower than reaction 10(b)). (7(b)) NH + $\mathbf{N H}=\mathbf{N N H}+\mathbf{H}$. Hanson and Salimian [34] use an estimate of $7.94 \times$ $10^{11} T^{0.5} \exp (-10000 / R T)$. This reaction has the same effect on their kinetics as reaction (7). Cohen gives a value for the rate coefficient of $10^{9} T^{1.5}$ and a discussion of the temperature dependence of reactions $(7(\mathrm{a})),(7(\mathrm{~b}))$, and $(7(\mathrm{c})) .(7(\mathrm{c})) \mathbf{N H}+\mathbf{N H}=\mathbf{N H}_{2}+\mathbf{N}$. Hanson and Salimian give an estimate for this rate, $2 \times 10^{11} T^{0.5} \exp (-2000 / R T)$ that indicates that it is probably not significant in the modelling of $\mathrm{NH}$ and $\mathrm{NH}_{2}$ profiles compared to reaction (7).

(8) $\mathbf{N H}_{2}+\mathbf{M}=\mathbf{N H}+\mathbf{H}+\mathbf{M}$. This reaction does not have a significant effect on the measured concentration profiles of this work. The rate coefficient used is that of Hanson and Salimian [34]. Miller [12] uses a rate coefficient of $2 \times 10^{16} T^{-0.50}$ for the reverse reaction. This is an order of magnitude less at $2500 \mathrm{~K}$ than the estimate of Hansion and Salimian. (8(a)) $\mathbf{N H}_{2}+\mathbf{M}=\mathbf{N}+\mathbf{H}_{2}+\mathbf{M}$. This is an unlikely product route that has not been considered in the combustion literature.

(10) $\mathbf{N H}_{2}+\mathbf{N}=\mathbf{N}_{2}+\mathbf{H}+\mathbf{H}$. Whyte and Philips [40] have measured this rate coefficient at room temperature and give a rate coefficient of $7.3 \times 10^{13}$. This rate coefficient is used by Miller [12] as well. (10(a)) $\mathbf{N H}_{2}+\mathbf{N}=\mathbf{N N H}+\mathbf{H}$. This reaction should be kinetically indistinguishable from reaction (10). Cohen [17] gives a rate coefficient value of $10^{14}$. (10(b)) $\mathbf{N H}_{2}+\mathbf{N}=\mathbf{N H}+\mathbf{N H}$. This branching path is mentioned only by Roose [1]. 
(13) $\mathbf{N H}_{2}+\mathbf{N H}_{\mathbf{2}}=\mathbf{N}_{\mathbf{2}} \mathbf{H}_{2}+\mathbf{H}_{2}$. All the product branches of these reactants may play some minor role in the $\mathrm{NH}_{2}$ profiles under the present experimental conditions. It is not possible at present to place any strong limits on these reactions by kinetic fitting of the present data. A value of $5 \times 10^{11}$ given by Khe is quoted by Miller [12], Roose [1], as well as Hanson and Salimian [34], gives a value of $4 \times 10^{13} \exp (-1200 / R T)$. (13(a)) $\mathbf{N H}_{2}+\mathbf{N H}_{\mathbf{2}}=\mathbf{N}_{2} \mathbf{H}_{3}+\mathbf{H}$. Dean [21] give a theoretical estimate of $7.4 \times 10^{11} \exp (-2490 / R T)$ in good agreement with their flame data. They find it necessary to invoke this reaction to improve their modelling fits. (13(b)) $\mathbf{N H}_{2}+\mathbf{N H}_{2}=\mathbf{N}_{2} \mathbf{H}_{4^{*}}$. Dean gives a value of $2 \times 10^{11}$ and a theoretical discussion. (13(c)) $\mathbf{N H}_{2}+\mathbf{N H}_{2}=\mathbf{N}_{2}+\mathbf{H}_{2}+\mathbf{H}_{2}$. This rate coefficient is only described by Dove and Nip [2].

(14) $\mathbf{N N H}+\mathbf{M}=\mathbf{N}_{2}+\mathbf{H}+\mathbf{M}$. The measured profiles of this present work are not sensitive to this rate coefficient. Miller [12] has recently used a rate coefficient of $2 \times 10^{14} \exp (-20000 / R T)$. This estimate has been derived from fits to flame measurements and a sensitivity to $\mathrm{N}_{2}$ yields at temperatures near $1200 \mathrm{~K}$. Dean, Hardy, and Lyon [41] give a rate coefficient of $1.5 \times 10^{15} \exp (-35000 / R T)$ which they derived from their flame data at $1750 \mathrm{~K}$. (14(a)) $\mathbf{N N H}+\mathbf{M}=\mathbf{N}+\mathbf{N H}+\mathbf{M}$. This is an unlikely product route, mentioned only in the review by Hanson and Salimian [34].

(15) $\mathbf{N N H}+\mathbf{H}=\mathbf{N}_{2}+\mathbf{H}_{2}$. The measured profiles of this present work are not sensitive to the value of rate. Hanson and Salimian [34] give a value of $4 \times 10^{13} \exp (-2980 / R T)$ and Glarborg [16] use a similar rate. Miller and Bowman [12] have recently used a value of $1 \times 10^{14}$. (15(a)) $\mathbf{N N H}+\mathbf{N}=\mathbf{N}_{2}+\mathbf{N H}$. This reaction is mentioned only in the review of Hanson and Salimian.

(16) $\mathbf{N N H}+\mathbf{N H}=\mathbf{N}_{\mathbf{2}}+\mathbf{N H}_{\mathbf{2}}$. This rate coefficient does not have a significant effect on the measured profiles. Miller and Bowman [12] use a rate coefficient of $5 \times 10^{13}$. Hanson and Salimian [34] give a rate coefficient value of $2 \times 10^{11} T^{0.5} \exp (-2000 / R T)$, a lower estimate.

(17) $\mathbf{N N H}+\mathbf{N H}_{2}=\mathbf{N}_{2}+\mathbf{N H}_{3}$. Miller [12] gives an estimate for this rate coefficient of $5 \times 10^{13}$. Dean [21] gives an estimate of $10^{13}$.

(18) $\mathbf{N}_{2} \mathbf{H}_{2}+\mathbf{M}=\mathbf{N N H}+\mathbf{H}+\mathbf{M}$. Miller [12-14] notes that the diimide reactions are not well established in the literature, and gives an estimate of the rate coefficient for this reaction of $5 \times 10^{16} \exp (-50000 / R T)$. The present work is not sensitive to the value of this rate coefficient though this reaction contributes to the $\mathrm{H}$ concentration profile slightly. Dean, Chou, and Stern [21] use $3.4 \times 10^{12} \exp (-65000 / R T)$ for the unimolecular decomposition of this reaction and give a brief theoretical discussion of this rate. (18(a)) $\mathbf{N}_{2} \mathbf{H}_{2}+\mathbf{M}=\mathbf{N}_{2}+\mathbf{H}_{2}+\mathbf{M}$. This path is mentioned by Hanson and Salimian [34] only.

(19) $\mathbf{N}_{2} \mathbf{H}_{2}+\mathbf{H}=\mathbf{N N H}+\mathbf{H}_{2}$. Miller [12] uses a value of $5 \times$ $10^{13} \exp (-1000 / R T)$ as an estimate for the rate coefficient. Dean, Chou, and Stern [21], in effective agreement with Miller, give $10^{12} T^{0.5} \exp (-2000 / R T)$.

(20) $\mathbf{N}_{2} \mathbf{H}_{2}+\mathbf{N H}=\mathbf{N N H}+\mathbf{N H}_{2}$. Hanson and Salimian [34] gives an estimate for this rate coefficient of $10^{13} \exp (-1000 / R T)$ as does Miller [12].

(21) $\mathbf{N}_{2} \mathbf{H}_{2}+\mathbf{N H}_{2}=\mathbf{N H}_{3}+\mathbf{N N H}$. Miller [12] and Hanson and Salimian [34] use $10^{13} \exp (-3980 / R T)$ as an estimate. (21(a)) $\mathbf{N}_{2} \mathbf{H}_{2}+\mathbf{N H}_{\mathbf{2}}=$ $\mathbf{N H}+\mathbf{N}_{2} \mathbf{H}_{3}$. Only Hanson and Salimian mention this reaction path. 
Various other reactions are mentioned in the literature but have no notieceable effect on our kinetic modelling.

$\mathbf{N N H}+\mathbf{N N H}=\mathbf{N}_{2} \mathbf{H}_{2}+\mathbf{N}_{2}$. This reaction is only mentioned by Hanson and Salimian [34]. $\mathbf{N H}_{3}+\mathbf{N H}_{2}=\mathbf{N}_{2} \mathbf{H}_{3}+\mathbf{H}_{2}$. Dove and Nip [2] give a value of $7.94 \times 10^{11} T^{0.5} \exp (-21560 / R T)$ and this value is used by Roose, Hanson, and Salimian, and Yumura and Asaba. $\mathbf{N}_{2} \mathbf{H}_{2}+\mathbf{N}_{2} \mathbf{H}_{2}=\mathbf{N N H}+$ $\mathbf{N}_{2} \mathbf{H}_{3}$. This reaction is only mentioned by Hanson and Salimian [34]. Discussion of the role of $\mathbf{N}_{2} \mathbf{H}_{3}$ can be found in Dean [21], Miller [12], and Cohen [17].

\section{Bibliography}

[1] T. R. Roose, Ph.D. Thesis, Stanford University, 1981.

[2] E.J. Dove and W.S. Nip, Can. J. Chem., 57, 689 (1979).

[3] K. Holzrichter and H. Gg. Wagner, 18th Symp. (Int.) on Combustion, The Combustion Institute, Pittsburgh, 1981

[4] M. Yumura and T. Asaba, 18th Symp. (Int.) on Combustion, The Combustion Institute, Pittsburgh, 1981.

[5] J. V. Michael, J.W. Sutherland, and R. B. Klemm, Int. J. Chem. Kinetics, 17, 315 (1985).

[6] J. W. Sutherland and J. V. Michael, J. Chem. Phys., 88, 830 (1988).

[7] P. Marshall and A. Fontijn, J. Chem. Phys., 85, 2637 (1986).

[8] A. Y. Chang and R. K. Hanson, J. Quant. Spectro. Radiat. Transfer, 42, 207 (1989).

[9] J. D. Mertens, A. Y. Chang, R. K. Hanson, and C. T. Bowman, Int. J. Chem. Kinet., 21, 1049 (1989).

[10] K. Kohse-Höinghaus, D. F. Davidson, and R. K. Hanson, J. Quant. Spectrosc. Radiat. Transfer, 42, 1 (1989).

[11] D. F. Davidson, A. Y. Chang, K. Kohse-Höinghaus, and R. K. Hanson, J. Quant. Spectrosc. Radiat. Transfer, 42, 267 (1989).

[12] J.A. Miller and C. T. Bowman, Progress Energy Combust. Sci., in press (1988).

[13] J. A. Miller, M. C. Branch, and R. J. Kee, Comb. and Flame, 43, 81 (1981).

[14] M. C. Branch, R.J. Kee, and J.A. Miller, Comb. Sci. and Tech., 29, 147 (1982).

[15] J.A. Miller, M. D. Smooke, R. M. Green, and R.J. Kee, Comb. Sci. and Tech., 34, 149 (1983).

[16] P. Glarborg, J. A. Miller, and R. J. Kee, Comb. and Flame, 65, 177 (1986).

[17] N. Cohen, Int. J. Chem. Kinet., 19, 319 (1987).

[18] S. Salimian, R. K. Hanson, and C. H. Kruger, Comb. and Flame, 56, 83 (1984).

[19] S. Salimian, R. K. Hanson, and C. H. Kruger, Int. J. Chem. Kinet., 16, 725 (1984).

[20] T. R. Roose, R. K. Hanson, and C. H. Kruger, 11th Intl. Symposium on Shock Tubes and Waves, University Washington, 245 (1977).

[21] A. M. Dean, M.-S. Chou; and D. Stern, Int. J. Chem. Kinet., 16, 633 (1984).

[22] C.J. Dasch and R. J. Blint, Comb. Sci. and Tech., 41, 223 (1984).

[23] P. Dransfeld, W. Hack, H. Kurzke, F. Temps, and H. Gg. Wagner, 20th Symp. (Int.) on Combustion, The Combustion Institute, Pittsburgh, 1984.

[24] M. Yumura, T. Asaba, Y. Matsumoto, and H. Matsui, Int. J. Chem. Kinet., 12, 439 (1980).

[25] N. Fujii, H. Miyama, M. Koshi, and T. Asaba, 18th Symp. (Int.) on Combustion, The Combustion Institute, Pittsburgh, 1981.

[26] M. Yumura and T. Asaba, 14th Intl. Symposium on Shock Tube and Waves, Sydney, 1983.

[27] W. R. Anderson, J. Phys. Chem., 93, 530 (1989).

[28] A. Y. Chang, E. Rea, Jr., and R. K. Hanson, Appl. Optics, 26, 885 (1987).

[29] N. L. Garland and E. R. Crosley, J. Chem. Phys., 90, 3566 (1989).

[30] D. F. Davidson and R. K. Hanson, Int. J. Chem. Kinet., in press, 1990.

[31] R. J. Kee, J. A. Miller, and T. H. Jefferson, CHEMKIN; A General Purpose Problem Independent Transportable Fortran Chemical Kinetics Code Package, Sandia National Lab. Report No. SAND80-8003, 1980.

[32] A. E. Lutz, R.J. Kee, and J.A. Miller, SENKIN; A Fortran Program for Predicting Homogeneous Gas Phase Chemical Kinetics with Sensitivity Analysis, Sand 87-8248, Sandia Nat. Lab., Livermore, 1988. 
[33] R.J. Kee, F. M. Rupley, and J.A. Miller, The CHEMKIN Thermodynamic Database, Sandia Nat. Lab. Report No. SAND87-8215, 1987.

[34] R. K. Hanson and S. Salimian, Combustion Chemistry, W. C. Gardiner, Ed., SpringerVerlag, New York, 1985, Chap. 6.

[35] G. S. Bahn, Reaction Rate Compilation for H-O-N System, Gordon and Breach, 1968.

[36] S. W. Mayer, L. Schieler, and H.S. Johnston, J. Chem. Phys., 45, 385 (1966).

137] S. W. Mayer and L. Schieler, J. Phys. Chem., 72, 236 (1968).

[38] C. Morley, 18th Symp. (Int.) on Combustion, The Combustion Institute, Pittsburgh, 1981.

[39] O. Kajimoto, T. Yamamoto, and T. Fueno, J. Phys. Chem., 83, 429 (1979).

[40] A. R. Whyte and L. F. Phillips, J. Phys. Chem., 88, 5670 (1984).

[41] A. M. Dean, J. E. Hardy, and R. K. Lyon, 19th Symp. (Int.) on Combustion, The Combustion Institute, Pittsburgh, 1982.

[42] S. C. Ross, F. W. Birss, M. Verloet, and D. A. Ramsay, J. Mol. Spectro., 129, 436 (1988).

Received July 12, 1989

Accepted December 6, 1989 